\title{
Forum on the Art of Participation: A Curated Collection of Reflections, Explorations, and Instructions
}

\section{Cover Page Footnote}

Curated by Astrid Breel, Hannah Newman \& Robbie Wilson with Contributions from Adam Alston, Russell Anderson, Outi Condit, Emma Gee, Matt Fletcher, Jamie Harper, Sonia Overall and William Titley 


\section{CONTENTS}

Introduction - Astrid Breel, Hannah Newman \& Robbie Wilson 2

Explorations: What is Participatory Performance? $\quad 4$

The Shape of the Forum 5

$\begin{array}{ll}\text { The Forum Contributors } & 6\end{array}$

$\begin{array}{ll}\text { Reflections on the Forum } & 7\end{array}$

How to use the Twine $\quad 8$

$\begin{array}{ll}\text { Introduction Video } & 8\end{array}$

\section{Contributions: Reflections}

\#1 Powerful Encounters and Framed Intimacies: Reflections following the Forum on the Art of Participation - Outi Condit 8

\#2 The Butlers: Service as Participation - Matt Fletcher 15 \#3 'Brief Encounters': A Walk Around Canterbury with an Old Polaroid Camera and Some Out of Date Film - William Titley

Contributions: Explorations

\#4 Daring Greatly: Withheld Knowledge as Accidental Violence - Russell Anderson 29

\#5 Audience Participation and the Politics of Compromise - Adam Alston 33

\#6 An Argument for the Use of Systems Thinking in Participatory Drama Design - Jamie Harper

Contributions: Instructions

\#7 Walkshop and Soundshot - A Dérive and Participatory Performance - Sonia Overall 42

\#8 We Did That: (Not) @ Home II - Emma Gee 47

How to Make a Forum - Astrid Breel, Hannah Newman \& Robbie Wilson 54

Conclusion - Astrid Breel, Hannah Newman \& Robbie Wilson 


\section{INTRODUCTION}

This journal section contains the proceedings from the Art of Participation Forum, which was held at the University of Kent in May, 2016. The aim of the Forum was to invite both artists and academics to share their work in an unconventional format, somewhere between an academic conference and a performance festival. The Forum was organized by the authors of this introduction: Astrid Breel, Hannah Newman, and Robbie Wilson. At the time of the Forum, we were all $\mathrm{PhD}$ candidates in the Drama Department at Kent, all using participatory performance (PP) in our individual research and practice. Astrid looks at, and creates, participation in performance events, rather than at participation as part of the process of creating a work. Hannah has a more socially engaged approach, working in an immersive and applied setting, and Robbie uses PP to encourage playful interactions with one's environment. We wanted to have a broad range of academic and practical backgrounds represented so as to further our own explorations of participation, as well as expand others' views about what participation can be and do.

We wanted all attendees to contribute a provocation to discussion, a performance, or a workshop — while participating in each other's work throughout — so that there would be no passive observers or "audience" members. This ethos was manifested in our call for participation (or CFP - as opposed to proposals/papers ${ }^{1}$ ) and continues in this journal section; all content is contributed by Forum participants, with much of it reflecting on the Forum itself. The overall aim was to contribute towards a greater understanding of participatory practice by fostering inter- and intra-disciplinary conversations in a stimulating and informal setting, which refocused attention on the aesthetics of participation. Whilst we recognize the value of the impact agenda, ${ }^{2}$ we feel that it tends to dominate contemporary discussion of participatory art. The Forum sought to help redress the balance.

All Forum participants were invited to contribute to this section; the offerings from those who took up the invitation are collected here. Submissions could take the form of a version of their contribution to the conference or a response to the event itself and could be realized in any format or media. As organizers, we have collated the writing together into three sections based on what the contributions offer to the reader: reflections, explorations and instructions.

The reflections section comprises considerations from Forum participants on their own work and experiences of the event. Outi Condit discusses the role of power within participatory performance using examples from the forum as exhibits (The Butlers, Stephen 
Donnelly's DriftMob and her own contribution. Matt Fletcher considers the durational performance he presented, The Butlers, and how this fitted into the wider experience of performing in this role elsewhere. In "Brief Encounters," William Titley introduces his contribution and the process of creating this for the Forum and the role of "moments" in socially engaged projects.

The second section presents the contributors' explorations of their individual experiences at the forum, opening with Russell Anderson's discussion of his one-to-one performance, Daring Greatly, performed at the Forum. Within this performance, he received unexpected feedback about the potentially psychologically violent or manipulative elements within the structure of the piece, which led him to discuss this and the ethics of participatory work more widely. Adam Alston offers a video contribution, with a written accompaniment, in which he wants to provoke the reader/viewer to reflect on what compromise may be and what it might mean at the present juncture, exploring this in relation to participatory performance. Moving into a discussion of Nordic larp (Live Action Role-Play), Jamie Harper discusses system analysis and system design, arguing for it as a useful tool for designers of participatory drama, which enables meaningful impact on the fictional world.

Finally, the instruction section includes directions from two of the Forum participants for engaging with their work, which was carried out by participants of the event. Sonia Overall introduces her practice of the walkshop and soundshot. In this practice she details how to defamiliarize oneself with one's environment using pre-given directions and how to create a soundshot based on their experiences. Emma Gee presents her work (Not) @Home and discusses the instructions which asked participants to make their own "homes" in a shared space using masking tape and their personal possessions. She relates this to her own experiences of carrying out these instructions and taking part in the work alongside the other participants at the event. Further instructions for playful and participatory engagement are offered through the Twine version (GO TO TWINE) of this section of the journal issue. Twine is a web-based interactive non-linear storytelling platform. This Twine offers a selfguided approach to engaging with the contents introduced here, with opportunities for discovering "bonus content". The Twine aims to highlight different connections between contributions beyond the three sections and enables the reader to engage with the content in a non-linear and interactive way. 


\section{EXPLORATIONS: WHAT IS PARTICIPATORY PERFORMANCE?}

Given the considerable heterogeneity of arts practice termed participatory, which is not limited to performance, we had many conversations between the three of us about how to determine the terminology and scope of our CFP. We eventually decided on the intentionally ambiguous phrasing "participatory practices," so as to be as inclusive as possible. However, since participatory practices are inherently performative in nature (in its general sense of instigating action or performance ${ }^{3}$ ), and since performance is our disciplinary area, PP forms the focal point of the following discussion.

Participation in performance covers a wide range of performances practices: one-onone performance; immersive theatre; participatory performance; and socially-engaged theatre, to name a few. There has been much academic discussion of the terminology relating to participation and the status of participants. Gareth White defines participation most simply, describing it as when an audience member becomes part of the onstage action. ${ }^{4}$ Richard Sallis, whose work is situated in an applied context, suggests that participants are collaborators, ${ }^{5}$ which implies a greater degree of agency than in White's definition. Agency became a major theme during the Forum and is explicitly implicated in Rosemary Klich and Edward Scheer's notion of complex interaction (an ideal form of interaction that they have identified). They suggest that during complex interaction "participants collaborate with equal agency and have complete access to freedom of expression to create a work." Claire Bishop differentiates between participation and interaction by deeming participation the more social event, which "connotes the involvement of many people (as opposed to the one-on-one relationships of "interactivity')."7 One could argue that the greater the number of individuals involved the more complex their interactions, which would posit a tension between Bishop's and Klich \& Scheer's interpretations. In socially engaged theatre, definitions include the idea that "the audience co-creates the event." ${ }^{8}$ Co-creation again implies agency, but Harvie's use of the term audience could indicate limited freedom of expression. In immersive theatre, audience members become "active participants, collaborators, and co-creators, moving into the realm of audience-adventurers," 9 yet this does not necessarily entail that they concretely impact the work. Adam Alston suggests that immersive theatre participants impact the work as a result of being reframed "not just as someone subjected to affect, but as someone who co-produces affect." 10 Though the Forum could not hope to resolve these debates definitively, it aimed to elucidate certain lines of enquiry. 
As mentioned, we come from different performance practices which influence our individual definitions of participation. Astrid's research examines participation as an aesthetic practice, defining it as a work where the participants make material changes during the performance. Within such practices, her research identifies four key elements: the intersubjective relationship between participants and between participant and performer; the embodied experience of doing within the work; the creative contribution made by the participant; and the demand characteristics of being a participant (which determine the way participants approach being a participant). Astrid's research combines audience research with practice-as-research $(\mathrm{PaR})^{11}$ to enable a holistic exploration of the participants' agency as both an aesthetic and ethical aspect of participation.

Hannah's research is working with children on the autistic spectrum in multi-sensory, immersive environments. The participants (aside from being scientific participants in the study) are encouraged to co-create the action and narrative within the interactive environment. The contribution that the participants make to the performance varies greatly, depending on their individual skills and the nature of the condition. This means that some participants contribute greatly and become co-creators, driving the action and narrative forward, whilst others engage in a different way, co-habiting the environment with performers. This means participants may have less of a direct impact on the action of the performance, although their contribution is equally as important.

Robbie has developed a methodology he calls Popular Participatory Peripatetic Performance, or 4P for short. This takes the form of loosely-structured, comedically-inflected performance activities which facilitate performer-participants' (or perficipants') movements through their environment, with the aim of unearthing ludic (playful) affordances therein. There are three strands to Robbie's PaR: Perplexpedition, in which he approaches potential perficipants in the street and invites them to play with him; Wandercast, a performative podcast that takes perficipants on a ludic wander; and Spinstallation, a playfulness workshop which involves perficipants' collaborative creation of bite-size ludic videos. You can engage with, and take part in, the project by visiting his website, www.ludicrouspilgrim.co.uk

\section{THE SHAPE OF THE FORUM}

After receiving a wealth of applications from a wide range of artists and academics, we began to shape the forum, trying to find connections between submissions and provocations for discussion. We also wanted to give equal weighting to both academic and 
practical submissions. Participants were asked to either contribute a thirty-minute workshop or a five-minute provocation, reducing both artistic and academic contributions to twenty-five percent of their usual length. In addition to this, there was an opportunity for performance submissions to be shown in specific slots or as longitudinal performances throughout the event. We also had invited a Keynote Doer (Tassos Stevens) and Responder (Gareth White). In the spirit of increased dialogue between academics and practitioners, we suggest that the role of Keynote Doer, namely a respected practitioner who leads a practical keynote session, would be a welcome addition to university-based arts events. We also formalized the role of Responder - a respected academic who retrospectively comments on a particular paper or panel, implementing Gareth's contribution as a keynote plenary session.

The fact that all attendees were to contribute to a session, together with the limited timeframe of a day and a half for the event, meant that we had to restrict the number of participants, which created an intimate atmosphere. Tassos opened the forum with a demonstration of a participatory performance REMOTE (by Coney) $)^{12}$ and Gareth closed it, responding to what he had heard and witnessed across the two days and giving us practical tasks to try to collectively map the territory of Participatory Performance.

\section{THE FORUM CONTRIBUTORS}

\section{Day One:}

- William Titley (Brief Encounters) presented throughout the two days.

- $\quad$ Performance throughout the day by The Butlers, Matt Fletcher and Thomas Jancis.

- $\quad$ Keynote Doer with Tassos Stevens (Playing REMOTE - the Meanings of Interactions).

- $\quad$ Workshop with Outi Condit (Invitation and Response: How does Desire Guide Us?).

- $\quad$ Politics discussion with provocations from Adam Alston (Audience Participation and the Politics of Compromise) and Esses \& De Mesa (The Political and the Correct).

- $\quad$ Workshop with Kate Mail (How do Groups Limit their own Participation?).

- $\quad$ Outside workshop with Stephen Donnelly (DriftMob - A Game Exploring

Playfulness, Negotiation and Support in Public Space).

(Not) @ Home with Emma Gee running simultaneously with Russell Anderson

(Daring Greatly).

\section{Day Two:}


- $\quad$ Outside workshop with Sonia Overall (Walkshop and Soundshot - A Dérive and Participatory Performance).

- $\quad$ Spaces/Relationship between performer-participant with Eliel Jones (When 'Public' Becomes a Verb), William Lewis (Audience Affect and Transmedia Narratives) and Rei Poh (Dramaturgy of Space in Participatory Theatre). Practical session with Adam James (Tip of the Tongue, Teeth and Lips) with provocations from Jamie Harper (Meaningful Play in Live Action Participatory Performance) and Jaakko Stenros (Co-Created Meaning in Nordic Larp). Keynote Responder with Gareth White.

\section{REFLECTIONS ON THE FORUM}

The fact that all attendees were also both contributors and participants appeared to foster a sense of joint-ownership of the event, a feeling which was shared by all. Along with the ever-present threat of the mighty horn (our time-keeper), we feel that this sense of shared ownership contributed to the tightness with which the schedule was adhered to. We believe that the non-hierarchical nature of the event and the sense of joint-ownership were fundamental to its success and also to its originality. This notion of the joint-ownership and lack of hierarchical structure was present in feedback from one participant:

I think the loveliest thing was the absolutely non-hierarchical, peer-sharing, friendly \& fun nature of the event. I was discussing this earlier with someone else, in comparison to the traditional conference format - that conferences can feel very hierarchical and about the "transmission" of knowledge from the "haves" to the "have-nots," and that Q\&A challenges can sometimes be a bit aggressive. In comparison, the Forum was absolutely about a room full of equals from all kinds of backgrounds having a dynamic conversation - and I think this was seen in the fact that the most common shape for the room to fall into was a circle, instead of the podium/audience dynamic so familiar from conferences.

The wide variety of voices was highlighted by another participant:

What was incredible was the curation of each of the individual viewpoints and practices you brought together. I feel it was an important weekend because of the many voices in the space.

The fact that we had voices from both academia and the art world, helped foster conversations that perhaps would not have been present in other, more traditional, formats. This benefited the participants as there was a "realising [of] just how compatible aspects of written and theatre practice are, and can be." This, in combination with the dual status of 
attendees' as contributors and participants leads us to conclude that this element of the Forum format could be a significant development in arts research events.

We are aware that similar formats have been employed in continental Europe (for example, The Ludic Stance one-day conference, Academy of Performing Arts, Prague, September 2016); however, to the best of our knowledge, ours was the first event of this size and the first to be formally documented.

\section{HOW TO USE THE TWINE}

In the spirit of the Forum, which took a participatory approach to exploring the art of participation, we have also created a Twine [GO TO TWINE] This offers an interactive way of engaging with the material from this section of the journal by drawing out some of the themes and connections between the contributions and allowing the reader to follow different paths through the material. It is designed to be a playful way of engaging with the Forum responses and you may also be able to find the few bonus bits of material that are hidden within it! Enjoy!

\section{INTRODUCTION VIDEO}

https://youtu.be/C1aYMBpUnLQ

\section{SECTION 2: REFLECTIONS}

\section{Powerful Encounters and Framed Intimacies: Reflections following the Forum on the Art of Participation}

\section{Outi Condit}

Participatory performance practices are sometimes deemed relational, in reference to "relational aesthetics" designated by art critic and curator Nicolas Bourriaud in the late nineteen-nineties. But as recent critiques of participatory and immersive practices have suggested, it may not be enough to say that a piece of theatre or live art creates human relations and is subsequently co-created through those relations. In her critique of Bourriaud's construction, Claire Bishop proposes that instead of celebrating relationality as such, we should ask: what of relations are produced, for whom and why? ${ }^{1}$ As an artistic researcher and 
performer working with participation, I would like to add "How" to these questions. How are relations created in participatory performance, and how are the engaged bodies affected?

When performances or artworks deviate from what are often described as conventionally structured audience arrangements-keeping in mind that relational, immersive, participatory, and socially engaged works create conventions of their own-they engage with power in ways that are formative of the work. They create constraints and affordances that involve the audiences' agency and/or corporeal presence in their aesthetics and embodied politics, and these, in turn, play a part in molding the experiences and affective-discursive practices that become available for audience members and performers alike. Following Michel Foucault's analysis of power, one can argue that this is true of all practice. Power is omnipresent, pervasive, and always already situational and relational. However, in order to unpack how relational aesthetic frameworks differ from everyday life, perhaps it would be helpful to conceive of participatory performances as exceptional social spaces in which existing power structures and hierarchies are engaged with under slightly different conditions and altered rules. It may also be helpful to consider the power negotiations they incorporate as artistic and affective propositions and devices. Examining how power relations are worked with and through in participatory performance- how they intersect and entangle with existing social power relations and hierarchies - and how they are experienced by (different) audiences and performers, could offer a more nuanced understanding of the practices and politics of participation and the aesthetic/affective experiences they engender.

By positioning participatory performance practices as creation of exceptional social spaces, I do not mean to imply that these practices are necessarily empowering or positively transformative (even though such claims are sometimes made). I wish rather to suggest that the worlds created through performance are never separate or free from the politics of the everyday world, however much some makers may strive towards "total immersion," and that the embodied politics of participatory artworks engage with existing power structures and hegemonies in multiple, complex, affective, and aesthetic ways. A similar strain of argument has been put by contemporary theatre scholars: Adam Alston shows how the politics of immersive theatre aesthetics can be complicit in neoliberal value ${ }^{2}$ and Jen Harvie examines practices of audience participation in the context of neoliberalized cultural production. ${ }^{3}$ In this very short account, I would like to offer a complementary queered reading of the power positions and negotiations implicit in many participatory artworks and point to how the 
politics of participatory practice may also mold subjectivities, agencies, and affordances of affect on an immediate, embodied, and interpersonal level.

My approach is informed by my own embodied artistic practice as a performer and performance maker. I'm inclined to conceive participatory artworks through perceiving and instigating power positions and practices of power exchange, both when experiencing others' work, and when creating my own. I'm particularly interested in practices of negotiating and relinquishing control—which may happen through a variety of means, from psycho-physical techniques, to social transactions, to spatial and corporeal arrangements - and their affective reverberations. As seminal artworks like Marina Abramovic's Rhythm $0^{4}$ have shown, gestures of relinquishing control or power exchange do not necessary imply loss of agency. They can, however, create power polarities that have the potential to illuminate, subvert, and question (as well as ignore and uphold) effective power structures and hierarchies to do with gender, race, class, age, sexual orientation, ability, precarity, and other axes of identity, discourse and ideology. They can create affectively impacting conditions that play a part in framing experiences of vulnerability, risk, and intimacy, such as often come to the fore in descriptions of participatory performance. When I refer to a queer reading, I mean a reading that considers the inherent potential erotics of these performative power positions. By this, I don't mean to reduce performances that play with power polarities to mere hedonistic ventures. Rather, I wish to open up the artistic and subversive potentials, as well as the pitfalls, that come to play through the ambiguous pleasures and intimacies that this kind of participatory practice has the capacity to incite.

I would like to briefly apply this approach to two performances experienced at the Forum on the Art of Participation, as well as the workshop I offered in the same setting. It's not a symmetrical set up: I experienced these pieces as an audience participant within the constrictions of an academic conference environment; due to the same restrictions, I didn't collect participant feedback as a workshop facilitator, so I only have my own reflections to build on. However, I hope that these three different examples give a sense of what reading performances and practices of participation through negotiations of power and their affective entanglements may produce. Unfortunately, this account doesn't serve to highlight how the conditions created by participatory performance affects the performers, a narrative that's often absent. Luckily, in a subsequent contribution to the journal, performer and performance maker Matt Fletcher writes about his work The Butlers, creating potential for interesting double exposure. 


\section{The Butlers}

Participatory performance by Artifice Arts. Performed by Matt Fletcher and Thomas Jancis

As participants trickle into the foyer to sign in to the Forum, I'm already aware of the Butlers. Their presence has an effect on the space, standing as they do, straight-backed, by the wall, nonintrusive, yet with a penetrating at-your-service attendance. They're separate from the uneasy social buzz congregating in the space. I watch them furtively from the side.

I'm given a card. The Butlers offer services, excluding those that involve cost, illegality, or physical or emotional harm. The services are offered for free, but in order to enter the frame, I must ask for something, I must commission a service. Butler Jancis gives me no help in negotiating the rules and boundaries of the game.

-What do people usually ask for?

-Oh, all kinds of things.

He is friendly and noncommittal. The onus is on me--I am required to utter a request, and inevitably expose something of myself. There is expectation in the air, even if it's just mine. I'm already engaged in an affective relationship that feels strangely intimate.

Encounters framed through performance have a peculiar double nature, as interactions and affective responses are not only experienced and felt but also aesthetically appear as part of the artwork. And of course, the context and the nature of this event endow the situation with its own special flavor. We are all artists, practitioners, and researchers working with participation. This transaction is public, and will create a spectacle for our peers around us. I have performance anxiety!

I ask for a backrub. I'm a bit embarrassed about my choice, or disappointed in myself. How unimaginative of me. We don't know each other, and this is not a social space meant for touching. I ask to be touched, inviting a new level of intimacy, albeit a socially acceptable one. Is this a transgression, or simply a default solution? I work with bodies, and tend to seek physical contact to relieve social tension. Here we go! I have already revealed something of myself.

Beguilingly simple, The Butlers offers a frame that engages with power in complex and ambiguous ways. As non-British, I'm aware that it will be playing with tensions and signifiers concerning social class in the British context in more sophisticated ways than I can fully appreciate. Also, the gesture of offering oneself as a servant molds a position of intimacy. A servant may have privileged access to social boundary crossing (like performing mundane activities like washing or dressing a master's body) through being socially 
invisible. ${ }^{5}$ A servant is not really there; a servant doesn't really count. This possibility of invisibility and intimacy plays on my mind, as I wonder what Butler Jancis may have seen and been asked to do while in this role. As a good servant, he of course won't tell. At the same time, I feel incredibly uncomfortable being asked to occupy such a blatant power position, invoking class distinction, drawing my attention to the more subtle and taken-forgranted positions of service and privilege I inhabit. The performative exchange activates a complex mesh of power relations that give a sense of (potentially mutual) vulnerability and exposure, while gently troubling its social context. I wonder how the performance operates in very different contexts, and what would be the situations or surroundings in which it would collapse, become naturalized or illegible to the extent that it ceases to work as an art piece.

Butler Jancis' touch feels clumsy and a bit clammy. Or perhaps that's just me tensing up. My mind floods with better, cleverer requests. We are stuck in a bubble of time that I need to control. Has it been long enough? How much more should I ask for?

The feel of his hands lingers on my skin well into the day.

\section{DriftMob}

Participatory performance created and presented by Stephen Donnelly

The setup is simple enough, like a game of "follow the leader." Divided into groups of approximately seven, we are set to roam around the campus. Leadership rotates around the group, and is transferred to the next-in-line by squeezing someone's shoulder. According to the rules of the game, we either follow the leader, or whole-heartedly support them in whatever they're doing with cheers and undivided attention. Nothing is explicitly forbidden, but positive behavior or attitude towards fellow players is encouraged.

"Try not to get arrested or put each other in harm's way too much," we are told.

My experience becomes more about following than leading. Of course, there is the stress and worry of having to take command, and the inevitable one-up-man-ship, but for me, the most pleasurable and mesmerizing moments are the ones when I almost forget there is a leader--or even, that I am the leader. I happily jog away, following the group, becoming part of larger organism, accepted as one in many. I relinquish control--not to anybody in particular, not as a personal exchange, but to the whole group. As we jog about, climb trees, lie on our backs under benches, it occurs to me: there's an element of exclusion to this joy. We are one. We are an entity. We share a secret that bystanders are not part of. 
The group exhibits a powerful force; I can feel it when we run past someone, or when attention shifts and there's a moment of hesitation. What if we start following someone, imitating or intimidating them? The play remains amiable, but the potentiality for it to turn nasty adds a thrill of danger. It occurs to me that we are aptly named a Mob. Would this be as fun if we played in a deserted place, with no potential onlookers? Are we reliant on the presence of an audience? How much are we taking hold of the social space, making it ours, interjecting it with our play, while depending on the outsiders to hold the space for us? How are we negotiating with the outside world, as well as within the group? How is this negotiation informed by the power structures and hierarchies, within which we operate? How are styles of leadership gendered? How are abilities negotiated? For whom is this space meant, this privileged space, this campus area of the University of Canterbury, and how are we occupying it? In what ways is our game interpretable from the outside, and how much is that potential interpretation influenced by perceived social clues like race, class, age etc.? What if these variables were different? What if the game was performed in a different social environment? Would anything change? What are we bringing into the world with this ludic gesture?

\section{How Does Desire Guide Us?}

Workshop presented by Outi Condit

Now my voice is different. As a final (self-)reflection I present the studio work that I offered to facilitate at the Forum. It is a workshop on corporal intimacy through power exchange, and it is awkward, and I'm desperately nervous, because this institutional context is very different than the participatory performance piece from which it originates. I try to make sure that everybody understands that it is okay to step to the side during the session, that they can always step back in, and that sometimes it might even be useful to change the point of view.

The session consists of three variations, but for this response I will elaborate only on the first, simple, almost banal version of the exercise--one that rings familiar from performer training and children's play.

The instructions are as follows: half of the participants place themselves in the studio in whatever position they choose, and close their eyes. The others walk around and choose somebody whom they attempt to approach and touch, using different directions, tempos, and 
body parts. "approachee" (with their eyes closed) feels they are about to be touched they say "No." The "approacher" stops, and tries with somebody else.

Essentially this is a martial arts exercise, used to sensitize practitioners to 360 degrees sensory awareness. In the working group of the ritual performance Circle, ${ }^{6}$ we used it to tune the audience in preparation for embodied encounters within the performance. In this workshop, my intention is to direct the participants' attention towards the sensory, affective space between bodies in order to sense how bodies are experienced and molded through interaction--how they shy away and open towards touch; how desire, defined in the widest possible sense, moves bodies. Some people (myself included) love this exercise. Others find it creepy. In terms of power play, in all its simplicity, I find it fascinating.

This exercise contains a familiar technique so widely used in somatic practices (and occasionally in participatory performances) that it's almost taken for granted: the closed eyes, the removal of eyesight through blindfolds and darkened rooms. It's an interesting device, arguably pointing towards value-laden dichotomies like visual/sensual, thinking/feeling, active/passive, representation/experience. In this case, the closed eyes also trigger a power polarity that brings the issue of consent into critical light.

On a surface level, the question of consent appears straightforward enough. Participants are informed. They know it's possible to step out at any given moment. However, on the inside, as you're waiting with your eyes closed, not knowing when you might be touched and how, and who may be approaching you, it's not so simple. Within the container of this exercise, consent is implied, until explicitly revoked. With their eyes closed, the "passive" participants' bodies become sites of reception and response, exposed to the gaze and agitation of the "active" participants. They become "thingly," reduced to their bodies, their boundaries under negotiation and transgression. The "approachers," on the other hand, also become involved in complex negotiations with their own boundaries, implicit contextdependent expectations, and desires; a negotiation that is also influenced by socio-political variables like gender, race, age etc. The power polarity, in this case coupled with uneasy consent, molds the affective landscapes of the exceptional social space framed by this simple exercise, and brings about dynamics of vulnerability, risk, and transgression that may similarly come to play in more complex participatory artworks.

\section{Conclusion}

I've briefly reflected on three experiences from the Forum on the Art of Participation from the perspective of the entanglement of embodied politics, artistic agency, and affective 
experience. Each of these pieces warrants a more in-depth consideration, but for the purposes of this short response I hope I have managed to point out something of the complexity of how power positions may work in participatory performance. My approach is connected to my ongoing artistic research project in which I am searching for ways to close-read, question, and queer the embodied politics of the stage, both through artistic works and research-minded expositions.

\section{The Butlers: Service as Participation}

\section{Matt Fletcher}

As attendees arrived at the University of Kent's Forum on the Art of Participation in May 2016, they were greeted at the door by two immaculately dressed Butlers, proffering business cards which asked 'How may we be of service?' In formal Edwardian morning attire, their offer was to undertake anything that was requested of them (excluding tasks involving cost, illegality, physical or emotional harm - a judicious safety clause) during the course of the event. Butlers (Matt) Fletcher and (Thomas) Jancis then spent the day moving furniture, making announcements, holding doors, pouring coffee, distributing equipment, providing directions, going to the shops, giving massages - all guided by the same basic code of engagement: to be unobtrusively but attentively available, to be reassuringly useful as required, and to be relentlessly and disarmingly polite and respectful throughout.
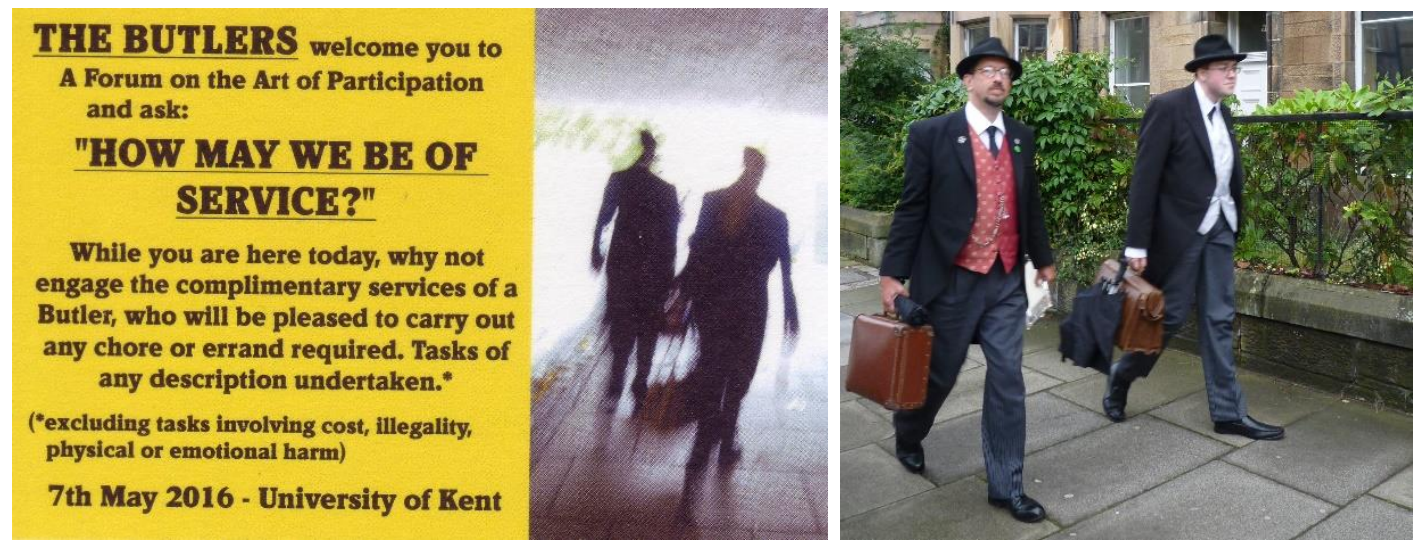

Reactions to the Butlers' presence at the Forum varied. Some were resistant to the idea of being waited upon, wary of requesting assistance, since this felt like a mechanism for "exploiting privilege." Through the perceived iniquity of the relationship between docile 
servant and dominant master/mistress, uncomfortable notions of class and race difference were exposed, and more than one person commented upon a postcolonial aspect to the work's engagement with the politics of power. Resistance to participation in (and therefore acquiescence to) such power relationships quickly led to at least two attempts to subvert the "game" being played, by endeavoring either to rebalance the roles ("I commission you to have a cup of coffee with me") or to reverse them ("I commission you to ask me to do something for you"). One person later reflected that the encounter "reminded me that I am 'service class'," and it is an abiding aspect of this work that it gently encourages participants to a surprising confrontation with and questioning of their own attitudes and prejudices.

Needless to say, combative and resistant responses were as welcome as eager embraces of the Butlers' offer-- many easily relaxed into the notion of having "servants" to do their bidding. Initial reticence, often stemming from a concern to think of something “interesting enough" for the Butlers to do, soon gave way to a host of prosaic but frequent commissions. Indeed, the Butlers swiftly became indispensable--particularly in the setting up of workshop sessions--and comments were made that "I could get used to this" and "I don't know what we would do without you." Several people noted the way that their own behavior seemed to alter in the Butlers' presence - they found themselves being strenuously polite in response, even adjusting their posture, use of language and tone of voice. A feeling of empathy for these altruistic, suited gentlemen was generated, and more than one participant described a warm sense of comfort and gratitude that pervaded them as a result of the Butlers' calm solicitude.

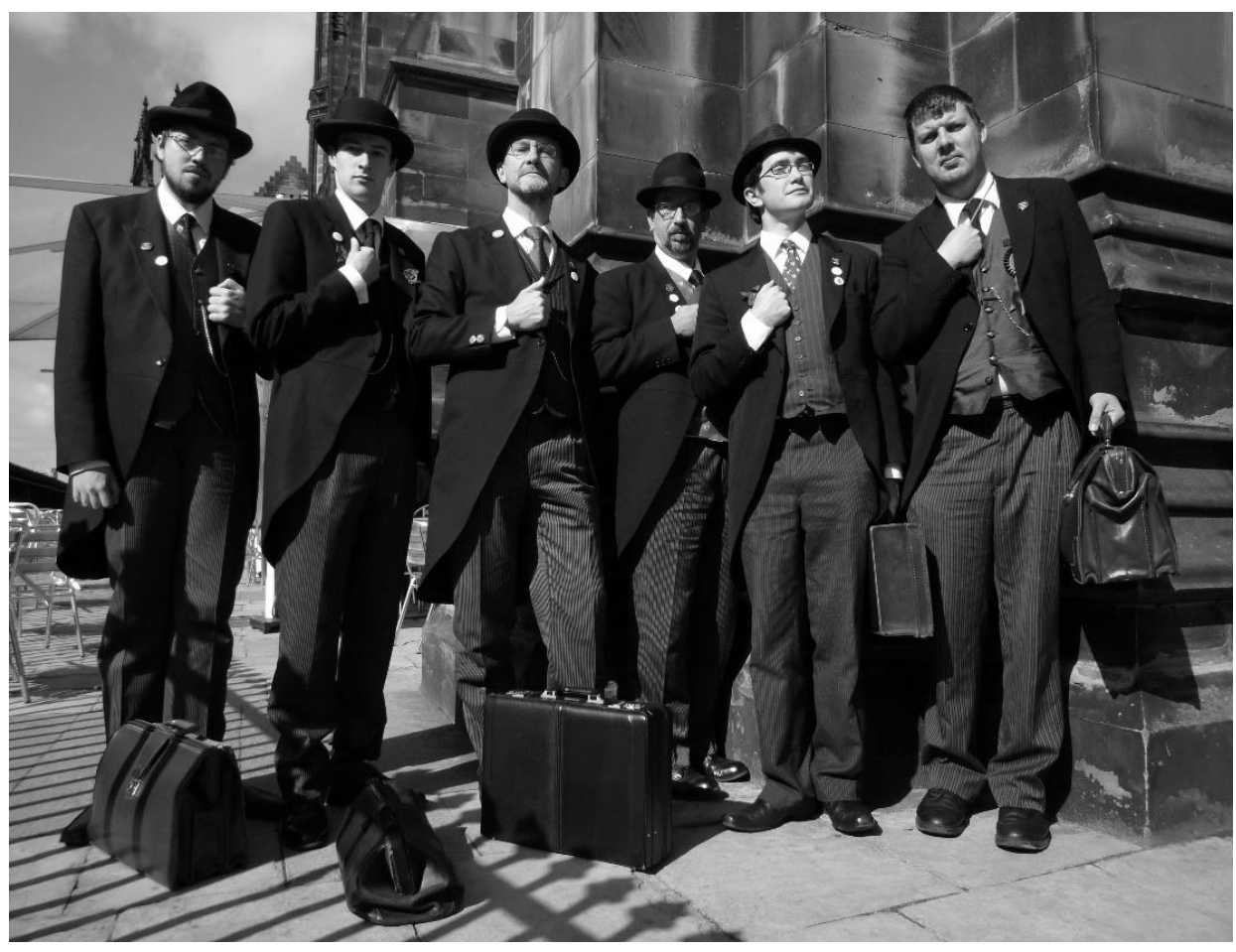


This range of responses corresponds with those encountered throughout the ten years of the Butlers' existence. Created in 2006 as an experimental working-through of Nicolas Bourriaud's concept of relational aesthetics, the troupe were originally conceived as a walkabout street act for the Edinburgh Festival Fringe. The idea seemed so far-fetched that there was no strong expectation of any requests for service being received, and the four initial performers had planned other activities to fall back upon, believing that their "performance" was dangerously over-dependent upon the creative input of willing commissioners. On both counts, they were to be proven very wrong.

The relationship at the heart of the Butler encounter was framed as a complex and problematized form of performance contract, with several stages of both offer and acceptance. In handing over a business card and asking "How may I be of service?," the Butler made an offer which the participant could choose to accept, reject or simply ignore. If the offer was accepted, the participant would then be required to make an offer in return - "I would like you to do such-and-such for me" - which the Butler needed to accept in turn before the performance could proceed. This counter-offer might be made face-to-face in direct response to the Butler's initial approach, or might be delayed and conveyed later sometimes days later - by phone. If a third party were involved in the commission - for instance, if a message was to be delivered to somebody - then an additional layer of offer and acceptance would come into play. It was to be made clear at every stage of these contractual negotiations that no remuneration was involved and, in fact, if payment was offered at any time, it was to be politely but firmly refused (since the work was predicated on the notion of service freely given). This construction not only made all parties highly active and complicit collaborators in the performance, but furthermore worked to pass creative control of the work from the "performer" to the "spectator". In effect, the percipient became the maker and the Butler became their material, the marionette meekly executing their every whim and wish.

That first year, three general phases of reaction to the Butlers' offer of service were identified. The initial phase was disbelief, a refusal to comprehend what was being offered and how it might constitute a performance at all. This was frequently followed by distrust, a wariness stemming from a niggling anxiety that there must be some hidden catch or trap in the offer. Quite often, people did not get beyond this phase. But if they did, the final response was one of delight, an enthusiastic stepping into the "game" which usually resulted in a commission. Indeed, at times a Butler encountered someone who leapt straight to this third phase, and these were generally the respondents who most playfully and inventively engaged with the work. 

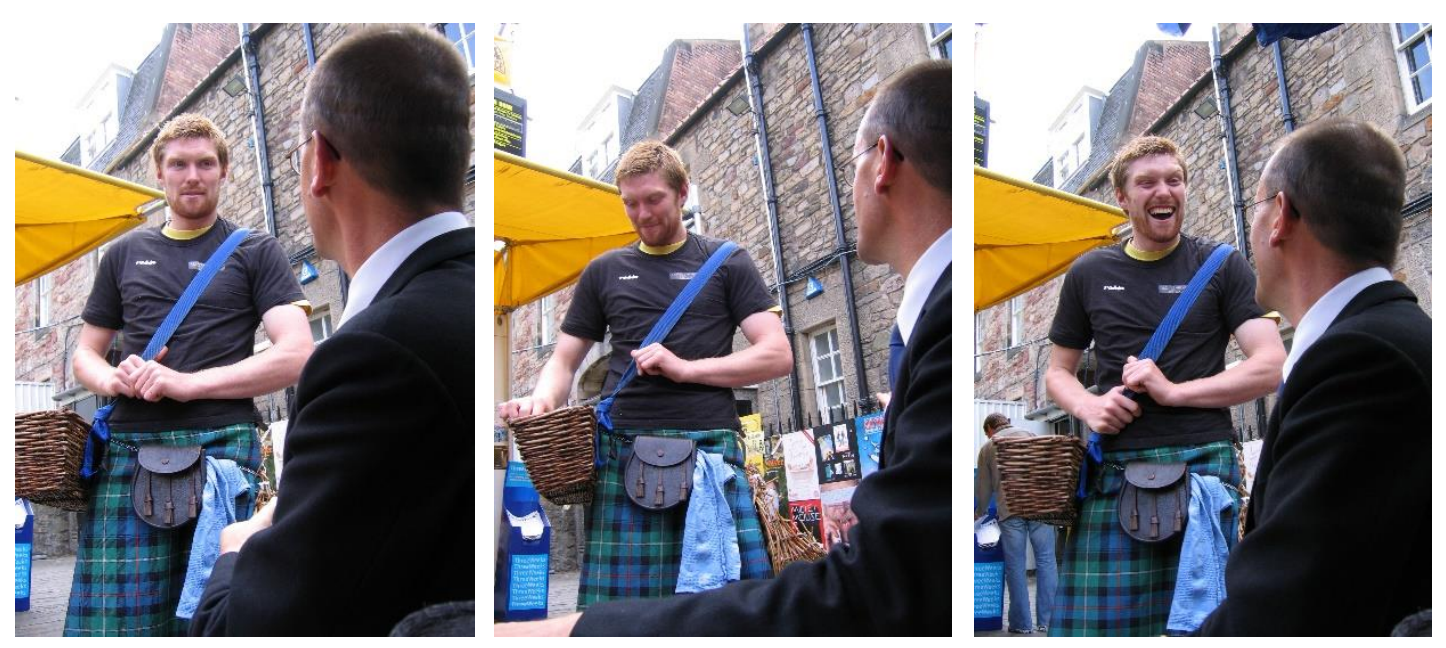

Contrary to expectations, large numbers of requests for service were received, and it was genuinely surprising to see how trusting commissioners were, inviting Butlers into the most intimate aspects of their lives and homes, even though these performers were effectively complete strangers. It seemed that the formal garb, respectful demeanor and perceived professionalism of these 'characters' had the ability instantly to put people at their ease. Apartments were cleaned, shopping carried, breakfasts cooked, drinks served, messages delivered (including a marriage proposal), research conducted, luggage transported, doors manned, songs sung, dresses hemmed, dinner tables waited, photographs taken, watches repaired, litter removed, flights booked, shows teched, dates arranged and umbrellas held. Many of these tasks were accompanied by a joyous sense of intense sharing, which frequently triggered a visceral emotional reaction from Butlers and commissioners alike. Somehow, in the simplicity of the action, and in the gentle way that it was both offered and executed, a profound connection was being momentarily made, and feedback attested to a lasting impact that the work often had on those involved.
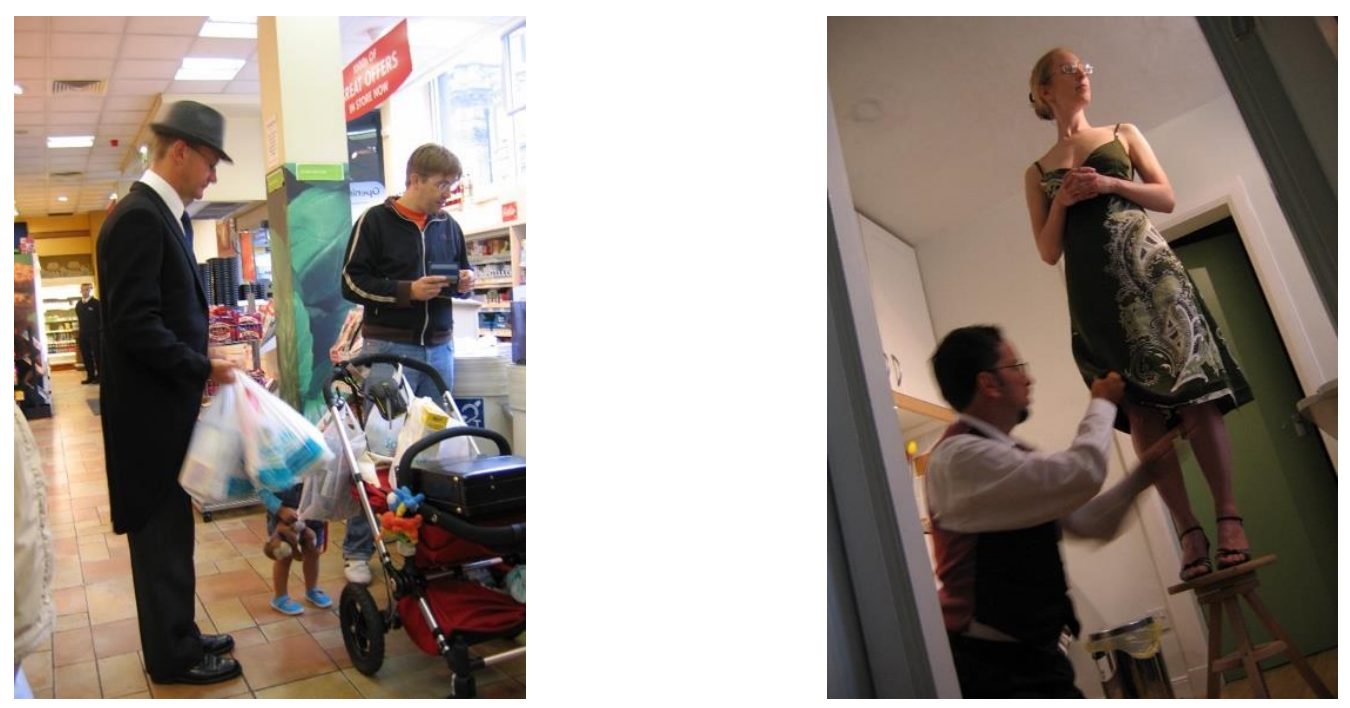
Most surprising was the discovery that a commission did not actually have to be undertaken for this impact to be felt. The mere act of talking to people about the Butlers and their offer was often sufficient to produce a strong response, and this conversation rapidly became an intrinsic and pivotal part of the "act". It seemed that the idea of the "performance" was almost as affective as the performance itself, and that it was the perceived altruism of the work which made the strongest impression. In an age ostensibly marked by commercialism, greed and a lack of courtesy, the Butlers' offer acted as a keenly felt panacea. The questions most regularly asked were "Why are you doing this?" and "What do you get out of it?," symptomatic of a contemporary suspicion of the selfless gesture or act of kindness. Such questions also drew attention to an increasing preoccupation with product rather than process, and to a loss of confidence in the "thing in itself", the action for its own sake.

One other observation was made in that first year, and has been ardently acted upon since. Anybody performing in very public places such as the street knows that they must be wary of those who can disrupt, undermine, and ultimately destroy the performance; most especially those who feel some sense of ownership of the public space and therefore see the performer as an interloper or trespasser.
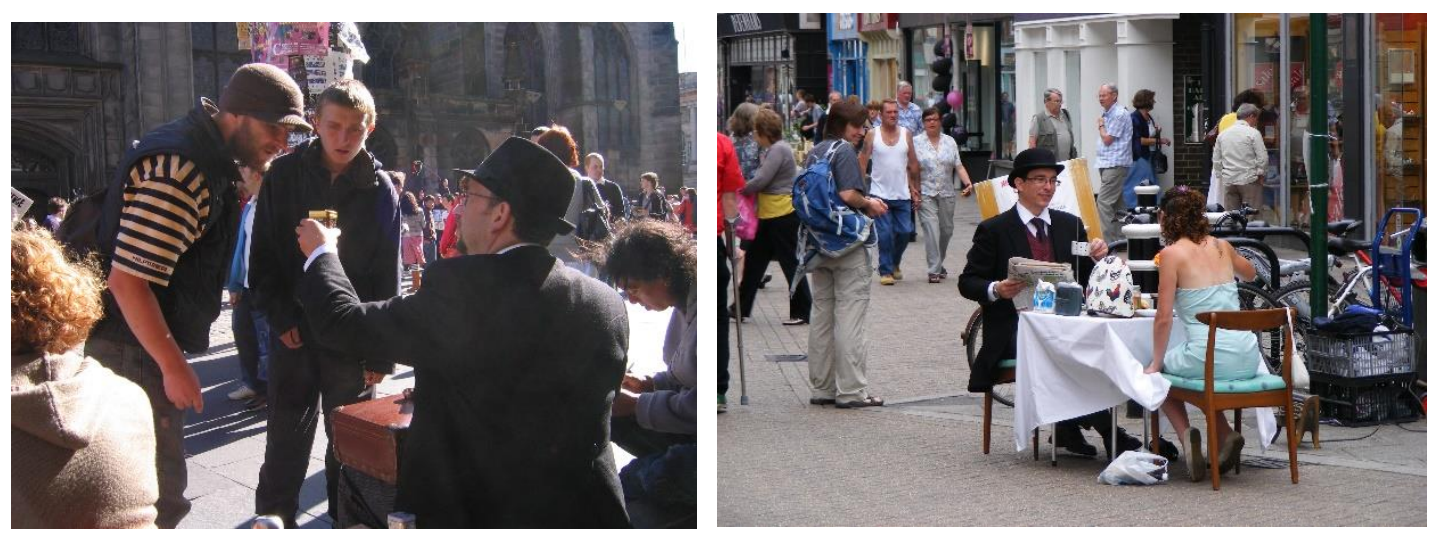

What the Butlers noticed was that their "characters" had the effect of melting resistance among such groups. Their combination of sartorial elegance and benign servility seemingly acted in two ways; to cast the Butler as a member of the "underclass," without power or authority, and thereby to remove those characteristics against which potential trouble-makers might try to push. The result has been a remarkable freedom to engage the broadest range of participants in the Butlers' ongoing work. 

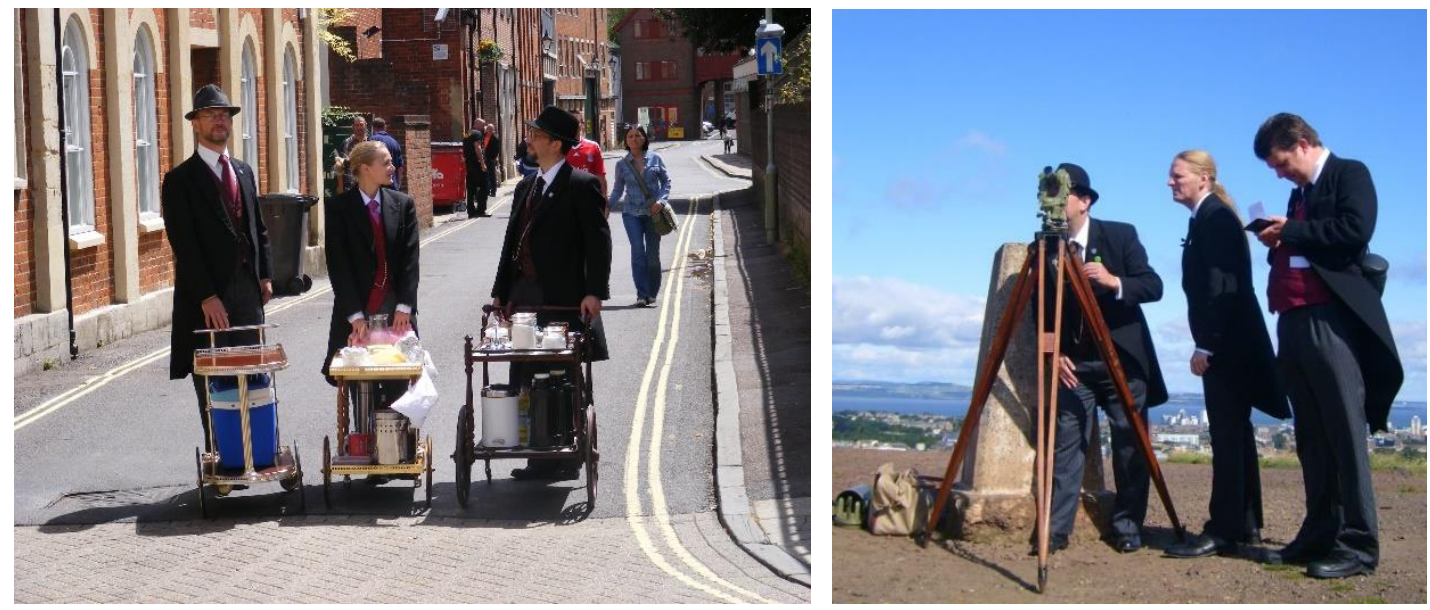

Over several years, the potential of the Butlers as an interactive performance device has been tested and expanded at a range of festivals, conferences and events across the United Kingdom and further afield. The idea of service has been enlarged to include activities of which people did not know that they had a need - the calculating of hat size, the measuring of altitude above sea level (using old-fashioned surveying equipment), the reading of William McGonagall poetry. Each Butler has developed their own particular specialisms, including such things as the reciting of bedtime stories (accompanied by cocoa), the making of journeys and the purveying of close-up magic. There has even been a performance offshoot - the Science Butlers - in which the same characters are used in an educational context to convey the wonders of everyday science. Most recently, the Butlers have been using telescopes to allow the public to communicate over long distances (an analogue texting service), culminating in the use of astronomical telescopes to send messages using the Murray Shutter Telegraph system, for the first time in more than 150 years. And, of course, whatever happens, tea must always be taken at four.
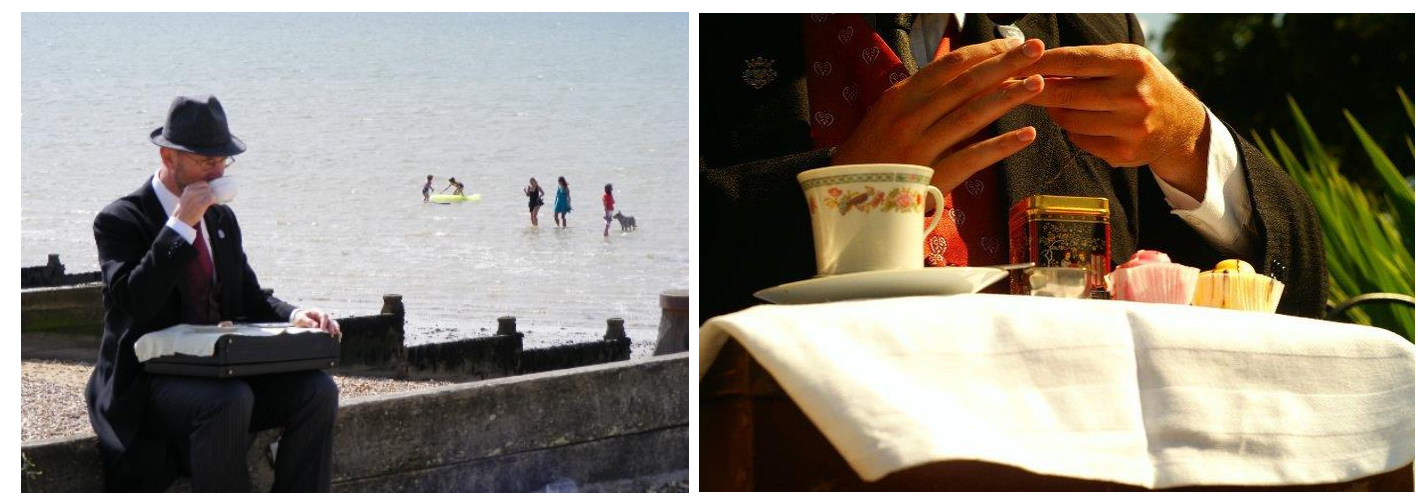

That the Butlers could be of service at the Forum on the Art of Participation was both a great pleasure and a fascinating privilege, as it provided the opportunity for the concept to 
be interrogated alongside other current models of performance participation. It was interesting to see the extent to which rule-based gaming structures are being utilized to both invite and control participation, something which is not a feature of the Butlers' construction. With their highly improvisatory approach to interaction with their "audiences," the coding of the work is limited to general principles regarding butlerial behavior and responses, and participants largely contribute without guidance or prompting. As an artefact, the resulting collaboration is consequently rather nebulous and ill-defined, more an experience than an art object, with deliberately unspecified performance outcomes since each respondent is invited to take from the encounter what they please. The personal and fleeting nature of the work makes it difficult either to commodify or document, and attempts to scale up the project have proven both problematic and inadvisable. Indeed, over time the performers involved have tended to gravitate towards the more private and the more invisible, taking the work further underground, although often making the performance encounters more intense and meaningful.

Aspects of the Butlers' approach to participation do seem to lend the experiment continued relevance and currency, in particular their focus on agency and publicness, both elements discussed by Gareth White at the end of the Forum, as he attempted to model a tentative rubric of ways to analyze participatory performance. The idea of agency had been addressed earlier by William Lewis, who had questioned whether performance which calls itself "participatory" truly gives audiences agency, or merely makes them feel like they have agency. The wish to cross this barrier into "free" participation lies at the heart of the Butlers' approach, as illustrated by the following brief example. On the first World Book Night in 2011, a group of Butlers appeared with an armchair and a pile of books in the center of Southampton, and began reading out loud to the passing shoppers. Anyone who showed an interest was offered a book. A group of teenagers gathered, intent on mischief, but got caught up in the story being told and ended up sitting in a semi-circle around the armchair. One of them suddenly drew attention to the power relationship which we had established: "Hey, how come you get to read, and all we get to do is listen?" Told that he could read too, as long as he sat in the armchair, he hesitantly agreed. As he began to recite the story to his gathered friends, the Butlers quietly walked away, their job done. 


\title{
Brief Encounters: A Walk Around Canterbury with an Old Polaroid Camera and Some Out of Date Film
}

\author{
William Titley
}

In this paper, I attempt to reveal the potential of the seemingly insignificant encounters that could hold the ingredients for transformative moments in participatory art projects.

My art practice evolves around engagement with people and place, and relies on reflective personal journal entries to help evaluate situations and interactions. Consequently, my process is heavily dependent on chance encounters with other people; encounters which ultimately affect the creative materials of everyday life, such as dialogue, a sense of the other, and situations.

In The Critique of Everyday Life (Vol. II) Henri Lefebvre distinguishes moments from the everyday, and suggests that the precursors to such moments "are there in embryonic form, but it is difficult to make them out with any clarity."7 Lefebvre's "moments" hold value and spring forth from everyday life only to fail, ultimately fading away and returning us back to everyday-ness. It is the embryos of those moments that I am interested in revealing for this short paper. Using an extract from my personal journal, made while the experience was still fresh in my mind, and together with samples of instant photographs, I will attempt to pin down some of the "partial moments" I encountered during a walk around Canterbury in Kent.

Having used an old instant camera and some out-of-date film, the photographs exaggerate the impossibility of capturing the ephemeral quality of a moment. The dried-up chemical compound resists the camera rollers as it is pressed across the picture plane of the Polaroid object. The photo object (as opposed to the photo digital) is precious; each release of the camera shutter begins the demise of another chemically distorted image--first appearing before our very eyes, then slowly fading away, unnoticed. And just like my social practice, there is an element of chance in regard to whether it will lead to anything at all.

\section{Diary Extract - Brief Encounters}

Canterbury is a tourist trap, with gorgeous architecture and sites of historical significance around every corner. The city attracts visitors from around the world, and I found myself faced with a language barrier at the first hurdle. My French is far from useful 
and after a couple of attempts to make conversation with tourists it became clear that we couldn't understand each other, and that we were all transitory in the space.

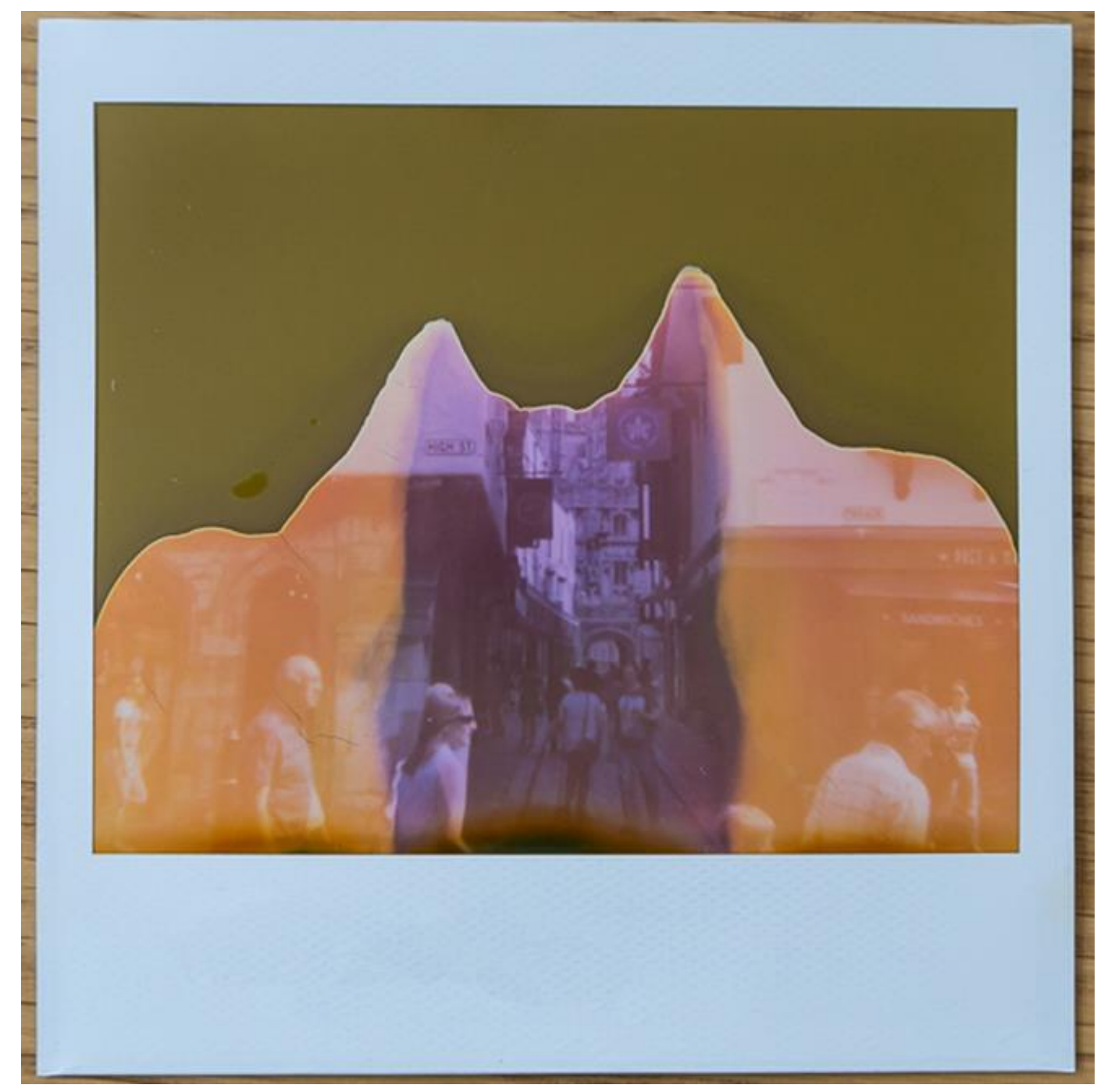

Polaroid 1: Busy street.

I grew less likely to engage with the tourists after assuming (rightly or wrongly) that they would be just as lost I was. Instead I chose professionals, who were easier to locate. Some people were on their way to/from work (wearing branded aprons, for example) and others interacted with me as a customer. I went to a café for a cup of tea. Upon asking the waitress about her favorite place in the city, she made an assumption about me, too; she went on to describe in great detail "where to get the best picture of the Cathedral." I went with her assumption that I was a tourist, and I adopted the same opening question when approaching tourists: developing rapport, albeit in an embryonic state (assuming the people I'm engaging with also want to photograph the Cathedral). 


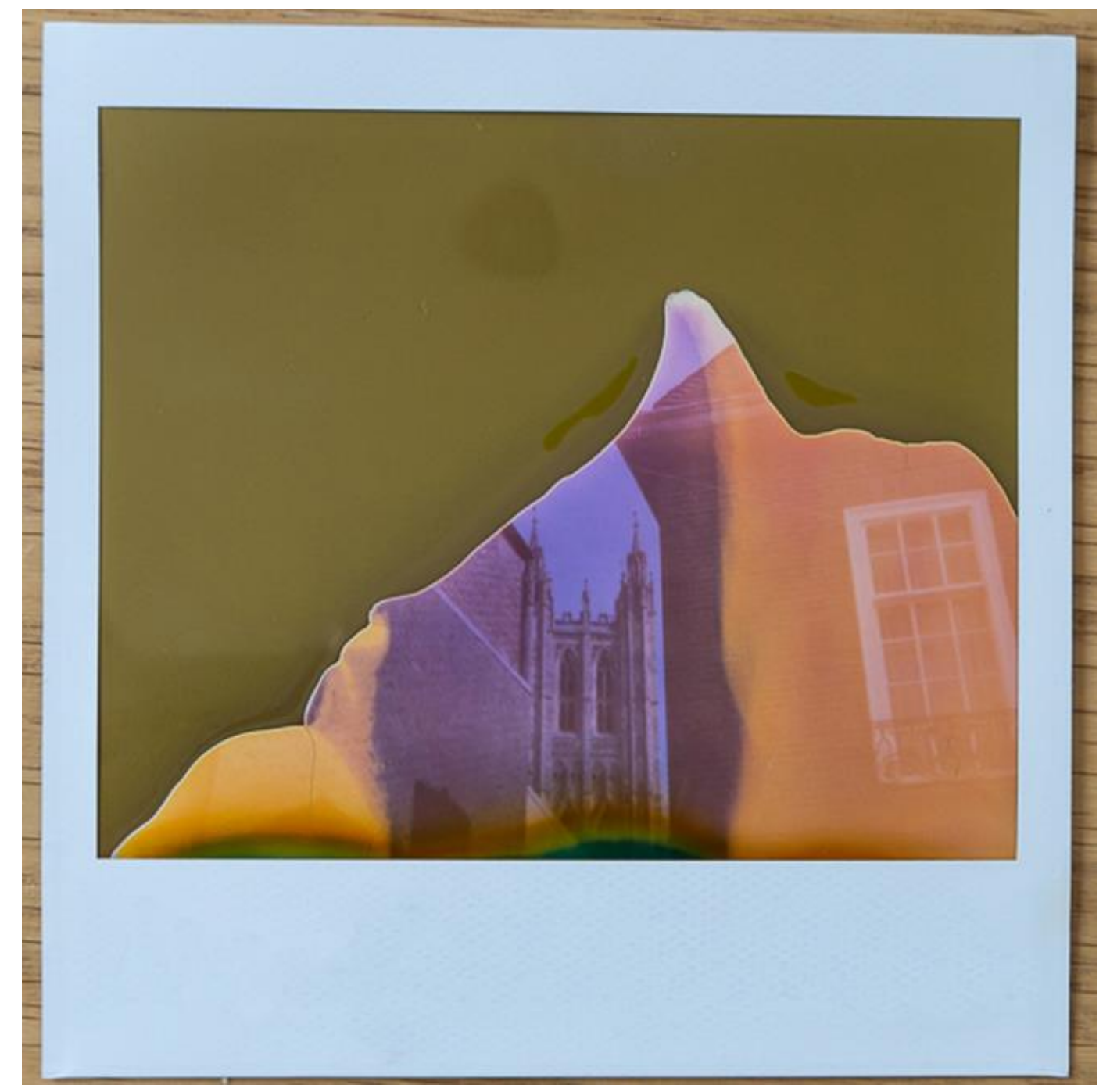

Polaroid 2: A glimpse of the Cathedral.

My chance to use this new opening line came and went before I could deploy it. I was enjoying a view of the river near The Friends House when a man who was trimming the grass on the riverbank emerged onto the bridge. He initiated a conversation about the battery life of his power trimmer. 


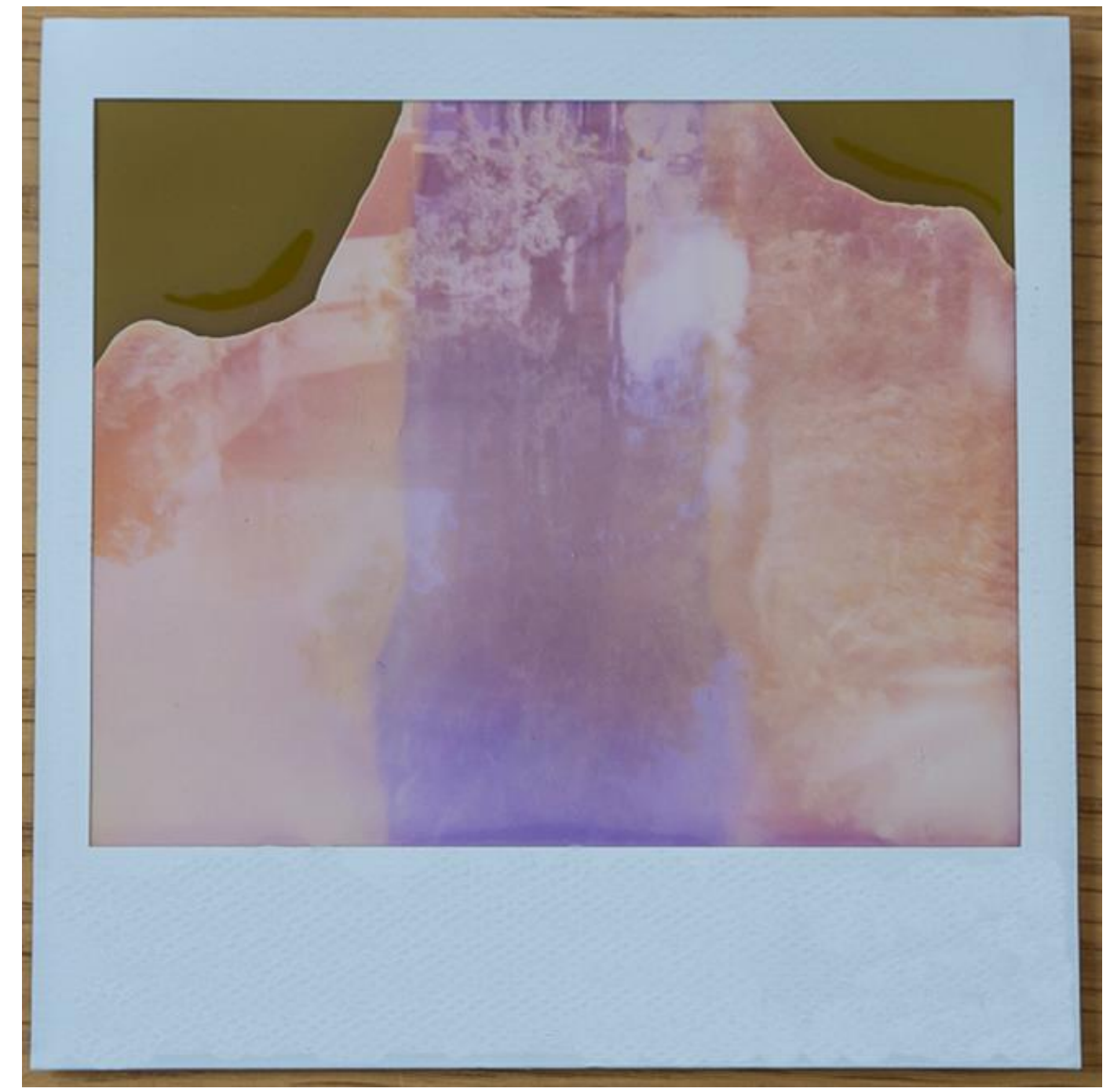

Polaroid 3: The riverbank.

He simply looked at me and said, “It's gone again and doesn't last very long at all, which is probably a good thing as there is a nest just there," and he pointed to the spot where his trimmers had clearly not touched the long grass. When I asked whether it was bees or wasps in there, he explained, "ducks, with eggs inside." 


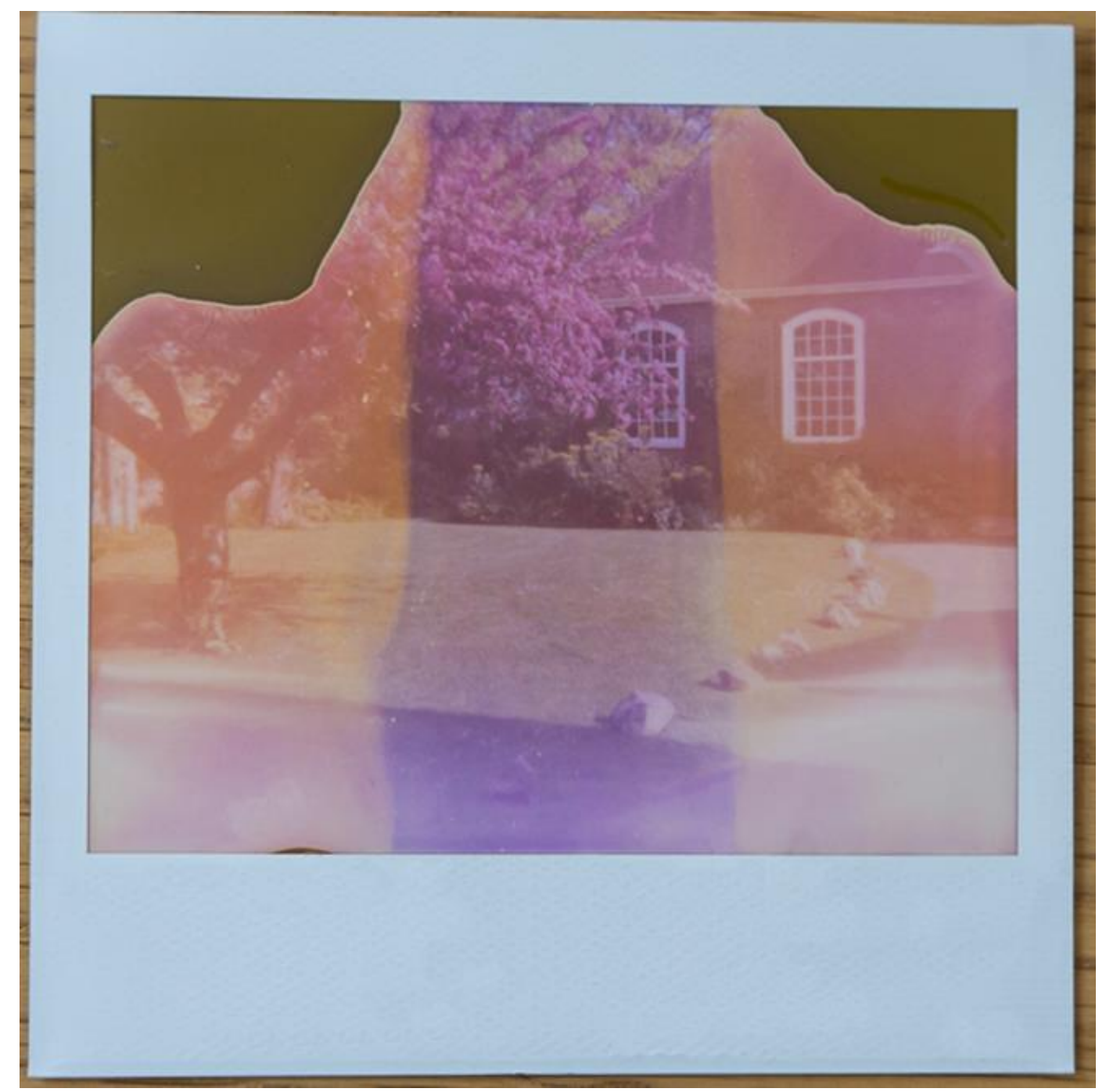

Polaroid 4: The Friends House.

I asked if he was responsible for the adjacent Friends House garden, commenting how gorgeous it was with immaculately trimmed trees and hedges. He started to walk away with the dead trimmer in hand, and without looking back, said, "well... it's not just me." He never did turn back, just kept walking away towards the garage on the far side of the Friends House. I felt a little rejected, convincing myself that maybe he had other things to do. I wonder what happened? Had I said something to offend him? Did he have somewhere to go? Did he not want to talk about "the others" who tended the garden, and if so, why not? Maybe he was deaf, and that once he had turned away, he couldn't hear a thing. After all, it was he who had started the conversation in the first place, and then casually walked away. I never got to ask him about the best place to photograph the Cathedral. 
Just then, a middle-aged couple arrived to see what I was looking at. "What a wonderful view," the lady smiled. "Yes, it's lovely," I replied. As she leant her elbows on the wall of the bridge, I shuffled along so she and her companion could see what I had been admiring: the reflection of an old building and a weeping willow tree, with sunbathers further up the distant banks of the river.

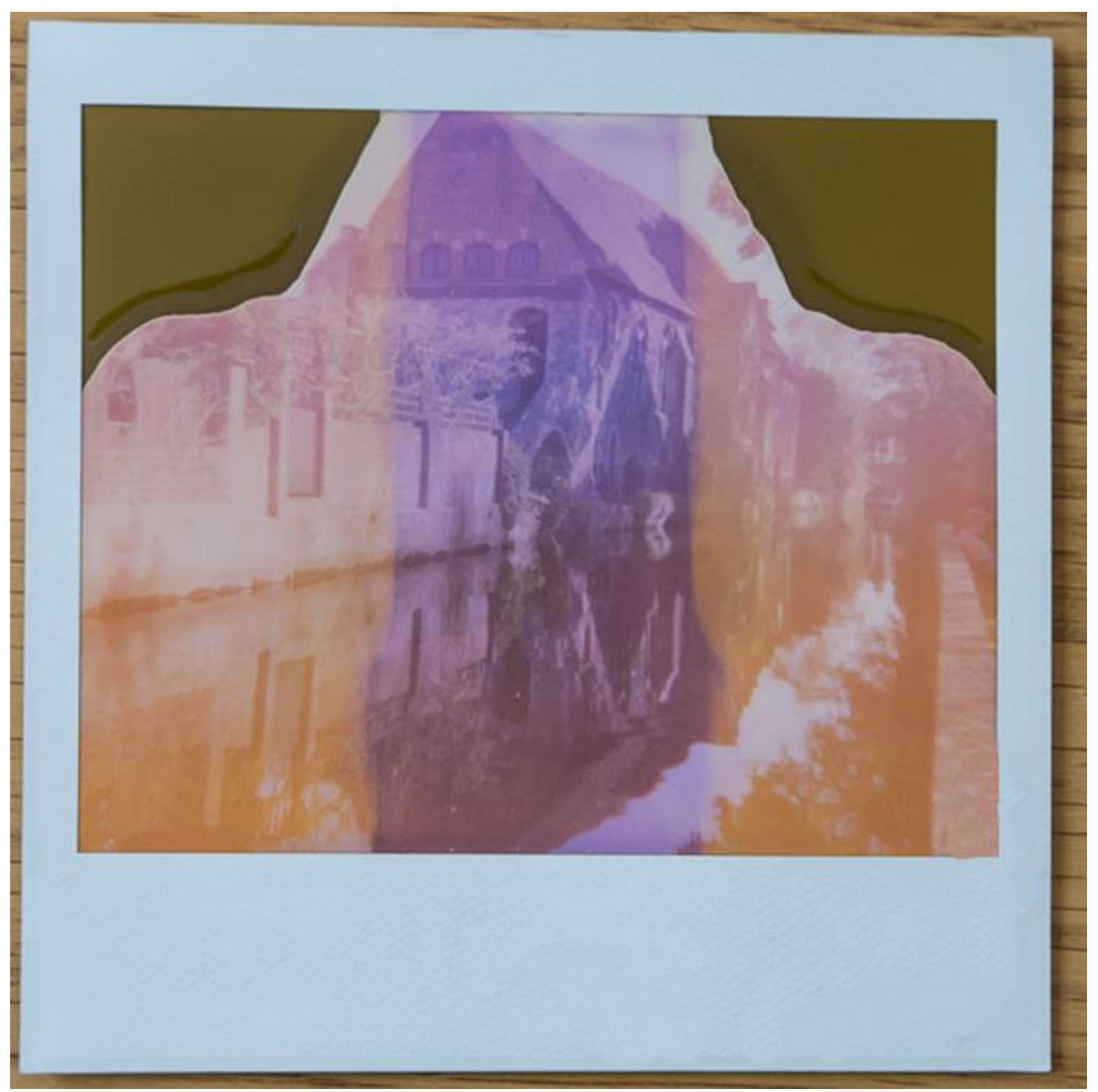

Polaroid 5: View from a bridge.

As the couple settled on the bridge, I immediately stepped back and slowly walked away to give them space to enjoy the view in their own space--their own moment.

\section{End of Diary Extract.}

In socially engaged art projects "moments" are considered as situations of personal change, transformative in some way. A participant, (the artist or a member of the community) 
can have a transformative moment where their perspective on life changes; often making changes to their everyday routine as a result of socially engaged art processes (educationally, politically, health, wellbeing, etc.). The relationship between artist and participant is crucial, and one that demands that the artist becomes a member (often temporarily) of the community.

"It is not by looking at things but by dwelling in them, that we understand their joint meaning" ${ }^{8}$ Michael Polanyi points out--it isn't enough, he suggests, to look at something in a bid to understand it, we must ultimately be able to empathize with the thing; seeing it in its own context is part of that process of understanding. Grant Kester, in his model of a dialogical aesthetic, acknowledges the importance of listening; together with Polanyi's theory of indwelling he helps to contextualize my interactions in the here and now, with local truths and "recognising the social context from which others speak, judge and act." 9

The instant photographs are abstract representations of my experiences (the first stages of a potential project) and while they fail to capture my social interactions, on a visual level they represent a series of potential moments which could lead, through further engagement, to enhanced states of "indwelling." Henri Lefebvre's moment is also heavily dependent on the materials of everyday life, as it "weaves itself into the fabric of the everyday, and transforms it," drawing on local resources/materials such as "something happening close by, something contingent and accidental." 10

Tim Ingold, when talking about the creative process of making, also identifies with this deep level of engagement with the everyday as "the artisan couples his own movements and gestures - indeed his very life - with the becoming of his materials, joining with and following the forces and flows that bring his work to fruition." ${ }^{11}$ My walk around Canterbury barely skimmed the surface of everyday life, but highlighted a straightforward strategy for mapping the interests of the artist as they attempt (often intuitively) to locate the elusive embryonic moments. The Polaroid photographs attempt to capture the partial totalities, halfbaked moments, and imagined potentialities--just like the "moment," the fugitive medium is destined to fail and fade away from the time/space in which it was created.

Arguably, the socially engaged artist is out to stop the moment from simply slipping back into everyday-ness without a trace--instead aiming to gather resources for a special moment that may change the everyday for the better (somehow benefiting the social / political / educational, health and wellbeing of participants). As it turned out, Canterbury tales were left untold, and we are now presented with a mere surface pattern of the place. 
In the context of socially engaged art practice, each encounter plays its part in the formation of dialogical precursors to transformative moments, even though those special moments may be a long time from occurring, or indeed they may never happen at all. The failing photograph, in its attempt to be an actual moment, becomes a prompt for further creative inquiry, which is informed by personal and intuitive responses in time and space.

Socially engaged art projects are heavily dependent on the slow passing of time: allowing for things to happen naturally, with the artist and participants relying on what Ingold refers to as "intuition in action."12 My projects evolve intuitively, they are live, emerging without rehearsal and no fixed design in mind. They work in and with the flow of life or, as Ingold might say, with the grain of the wood rather than against it. The artist's role as a facilitator of morphogenetic and dialogical approaches brings with it a tacit understanding of the creative process. It also brings a confidence that allows the art work to grow organically-in tune with the local environment and its people.

Tim Ingold suggests that the creative process is very much a social interchange between maker and materials, a communication of tension between both forces. The intersubjective exchanges between all the participants (including the artist) can occur on deeply intimate levels when given time to develop naturally; they are the building blocks of socially engaged practice, interweaving creative endeavor between art and life. It is at such profound levels where, at times, the blurring of everyday life and art go unnoticed. Sometimes the art of participation is stretched to the point of breaking down, but always something happens, and shared meanings emerge.

\section{SECTION 3: EXPLORATIONS}

\section{Daring Greatly: Withheld Knowledge as Accidental Violence}

\section{Russell Anderson}

In a participatory performance designed to generate trust and communion, how easy is it to accidentally pressure, manipulate, or inspire negative responses in the participant? My contribution to the 2016 Kent Forum on Participation was a one-to-one performance, titled Daring Greatly. This piece was developed specifically for the Forum, although a workin-progress performance took place at the Oxford-based arts event, Playground, in March 2016. Primarily designed as an investigation into generating trusting relationships in 
participatory work, the performance at the Kent Forum solicited an unexpected piece of feedback from one participant. This feedback highlighted potentially psychologically violent or manipulative elements within the structure of the work, and this paper is a reflection on the delicacy and care with which participatory work must be developed, if the artist intends to foster an atmosphere of openness, trust, and non-manipulation.

\section{Daring Greatly}

Daring Greatly was borne out of a personal interest in audience/participant investment in interactive work. Although not directly related to my wider research in interactive theatre, the project stemmed from the recognition that there are many different "flavors" of interactive audience: some are sincere, some are playful, some are reluctant, and so on. I was curious as to what we as artists can do to foster a sense of trust, communion, and willingness to take risks in our audiences, and Daring Greatly was a first attempt to address this question.

Named after Brené Brown's 2013 book Daring Greatly: How the Courage to Be Vulnerable Transforms the Way We Live, Love, Parent, and Lead, the performance was an exploration into shared honesty and vulnerability between performer and participant. Brown's book is principally concerned with the relationship between shame and vulnerability: how radical honesty and vulnerability can be an antidote to shame, and foster stronger relationships in both working and personal life. Given the connections between Brown's research and my own performance interests - radical honesty, vulnerability, trust, and risk taking - I developed a performance based around the concept of shame and vulnerability in a one-to-one setting, focused on one specific question: could I foster enough trust with a participant that they would be willing to share a deeply shameful memory or experience with me, within the space of ten minutes?

Daring Greatly works as follows: the participant enters a room where the performer is waiting for them (in this case, an office space). The performer greets them, thanks them for coming, and describes how the piece will work: 1) they will make an agreement that nothing discussed in this room will be shared beyond the performance; 2) the participant will have five minutes to ask the performer any questions regarding their experiences of shame or vulnerability, and the performer will answer with total honesty; 3) the performer will ask the participant a question, which they may choose whether or not to answer. Once the agreement is made (and sealed with a handshake), Debussy's Clair de Lune is played to mark the fiveminute question period. Following this interview, the performer asks their question of the 
participant: "are you willing to share with me something you are ashamed of, particularly if you have never told anyone before?" Participants are invited to leave written feedback about their experience.

At the time of writing, Daring Greatly has been performed twice, and both times has received extensively positive feedback regarding the risk taken in putting on such a performance--from appreciation of my vulnerability in the process, to many participants feeling a certain sense of liberation in being able to be honest about one of their deepest secrets. Although most participants choose to share their shameful experience, some do not, at an approximate ratio of $4: 1$. Of those who chose not to share, some expressed regret at their choice, and an admiration for my being willing to share in such an exposed manner.

After the performance at the Forum on Participation, however,I received a rather unexpected piece of feedback. A Forum participant asked me: "do you realise the inherent violence that exists in your piece?" Reflecting on this feedback revealed several structural points within the work that may be interpreted as having an off-putting, manipulative, or discomforting effect on the participant, and emphasized the attention that needs to be given when crafting participatory performances, particularly those based on mutual trust.

\section{A Brief Note on Ethics}

The question of trust is inherently linked to questions of ethics and audienceperformer relationships within participatory performance which, although not the primary focus of this reflection, is worth briefly exploring.

Any discussion of ethics in participatory performance runs the risk of mollycoddling audiences - after all, art does not have to be easy, or comfortable, and as Astrid Breel points out, "effective participation may mean putting participants in a challenging situation." However, she also clearly recognizes that

Ethics is inherently linked to participatory performance, which is dependent on the relationship between artist and audience. There are several aspects of this relationship that have ethical implications: the way the artist treats the audience member in the process of participation, the ethics of the situation or scenario in which the work takes place, the nature of the subject matter, and the participant's agency before, during and after the work. $^{2}$

Accompanying this, we should recognize that different audience members will have different psychological reactions to the possibility (or threat) of participation itself. As Gareth White states: 
People arrive at performances in very individual states of mind, and might have radically different attitudes to their capacity to perform, or to the potential for engaging in interaction to do them harm, depending on all sorts of contingent circumstances of the day, states of mental or physical health, or positive/negative anticipation of the performance event. ${ }^{3}$

The consequence is that any moment of participation may be received in dramatically different ways, and the presentation of situation, subject matter, invitation to participate, and the treatment of the participant are all elements that need to be carefully considered. It may be that your artistic intention is to explore difficult issues - such as freedom of choice and manipulation - in which case stretching the audience's willingness to participate or behave in a particular manner, or to treat them in particular (and perhaps unpleasant) ways may be appropriate to your work. If, however, your artistic intention is less confrontational to your audience - particularly if it is an attempt to foster trust and community - then consideration of the practicality of the audience-performer relationship should be paramount.

\section{Knowledge and Power in Daring Greatly}

Gareth White points out that "there are few things in the theatre that are more despised than audience participation. The prospect of audience participation makes people fearful." ${ }^{4}$ While it should be acknowledged that audiences who choose to go to one-to-one performances (and in particular, those at the Kent Forum on Participation) may form what Richard Schechner calls an "integral audience" being produced, and is supportive of it - the potential risks, uncertainty and fear associated with the prospect of participation may still be present.

These issues can be mitigated (or enhanced) through a variety of techniques, but the consensus on positive participation is that it should be offered and accepted, not forced or coerced. Josephine Machon, in discussing the related field of immersive theatre, states that "immersive work has to enable the audience to be willing participants," 6 [emphasis original], and relates a similar sentiment from Tassos Stevens, director of Coney:

we don't demand engagement but invite it so people can choose the level of engagement they're most comfortable with. You can stay on the outside of something and get a different experience from someone who's at the heart of it. ${ }^{7}$

This dynamic is much harder within a one-to-one setting, where the work essentially cannot continue if the participant refuses to engage. Whether or not a performer can rely on an integral audience to attend their work, a participant may feel pressure to conform to the structure of the work, despite their potential discomfort, misgivings, or fear. This was partly 
the case with at least one Daring Greatly participant, who related that they "felt a certain responsibility" to the work. Recognizing this, if the performer wishes to generate a sense of trust, they need to structure the work so as to mitigate these issues.

One of the primary imbalances between a performer and participant in any interactive work is that of prior knowledge, preparation, and rehearsal. After all, the performer has had time to develop the piece. Often, and particularly in the case of one-to-ones, has created it themselves--they will have written, planned, practiced, and perhaps tested out the piece prior to the performance. Additionally, with the exception of the debut, they will have the experience of previous iterations on which to draw.

A participant entering the piece, however, will have no such prior knowledge or experience. Even if they have been informed of the broad outline of what will happen, as in Daring Greatly, the withholding of information may be a cause for concern (particularly if the participant feels pressured into agreeing to a "what happens in the room stays in the room" agreement). In the case of Daring Greatly, the details of the final question asked of the participant are withheld until the end of the performance. Although the participant has been told they may choose whether or not to answer the question, it is understandable that a sense of pressure to participate may make a participant feel they "have to" agree to what they will be asked, even if they feel uncomfortable with doing so. This is exacerbated by the fact that they are in a one-to-one situation, there is a handshake-agreement, they are in the formal setting of an office, and the performer has been offering their experiences for five minutes. To a certain degree it may be much harder for them to say no - to work against the perceived "correct" outcome - than to tell a shameful memory.

The question of potential manipulation (however unintentional) reveals the extent of the power imbalance caused by the aforementioned knowledge imbalance. At its extreme, the imbalance of power between participant and performer has the potential to be damaging. White outlines this here:

there is a capacity for audience participatory theatre to be distinctly unethical, to manipulate participants into situations they did not anticipate or were not informed about and which expose them to significant public embarrassment or the revelation of private material. $^{8}$

White also raises the threat of public embarrassment and reputational damage as being of particular concern:

when participatory theatre invites performances from audience members, it presents special opportunities for embarrassment, for mis-performance and reputational damage, such that the maintenance of control and the assertion of agency that protects 
this decorum is important to the potential audience participant, especially at the moment of invitation. ${ }^{9}$

In Daring Greatly, concerns about the potential for private information to be "leaked" was raised by many of the participants. Questions were asked about whether or not we could be overheard by the next participant waiting outside. Participants raised concerns regarding the placement of the feedback book (on a chair outside the performance space), where it might be read by passers-by. Reassurances were sought that I was being honest when saying that the conversations in the performance would never be shared, and that the conversation was not being recorded in any way. These questions revealed an underlying concern from participants regarding the risk of exposure outside of the performance space, and as such the risk they felt they were taking by agreeing to participate.

It is worth noting that none of the above issues proved to be overwhelming problems for the Forum performance. I received primarily positive feedback about the experience, and that the intended sense of trust and communion was successfully fostered, even with those who chose not to share their own shame. Indeed, the participant who raised the question of inherent violence in the first place had a mostly positive response to the rest of the performance. It is these small details, however, on which "successful" participation may either stand or fall. Both times Daring Greatly was performed, it was with some form of integral audience, with participants who had an interest in this kind of work; most had experience making artistic work themselves. It might be possible that a more general audience would feel these issues of imbalance and discomfort more acutely. Of course, that statement is purely speculative, but it suggests that more work could be done to ensure a smoother and more positive experience for participants.

As can be seen, then, Daring Greatly contained several elements which may have unintentionally led to moments of discomfort, manipulation, or the feeling of coercion to participate. Although almost all of the feedback to the work was positive, and participants did recognize that "it was an option to commit to talk" (an option which some refused to take), the fact that the piece contained these elements, when its intention was to foster trust and communion between performer and participant, highlights the care and consideration that must be taken in all aspects of developing participatory work. It is still to be determined whether Daring Greatly will continue beyond the Kent Forum, but if it is to be developed further, significant structural changes will take place in order to try to avoid the issues discussed above, and to try to lead to a piece absent (or as close to absent as possible) of manipulation, coercion, pressure, of the fear of participation. 


\title{
Audience Participation and the Politics of Compromise
}

\author{
Adam Alston
}

\section{Video Documentation:}

https://youtu.be/q-fSwKyAYRw

I've been thinking a lot over the past few years about the state of socialism - and state socialism for that matter - and what it has come to represent. More specifically, I've become interested in notions of antagonism ${ }^{10}$ — and especially dissensus ${ }^{11}$ — as conceptual and critical tools to aid the analysis of participatory and immersive forms of theatre, as well as performance more broadly conceived. ${ }^{12}$ But, I've also become troubled by what the notions of an "antagonist" and "antagonism" might actually mean. The more immersive, participatory and game-based theatre that I went to see, the more I found people who, politically speaking, at least, were quite similar to me. Who were the antagonists here, I thought? Is theatre - at least this kind of theatre - really the place where we're likely to find them? And yet, we audience members - still found ways to squabble in performances like Coney's Early Days (of a better nation), and Kaleider's The Money. This was not antagonism along the lines articulated by the post-structuralists, and it was not a squabble between antagonists in the more conventional sense (hostility toward an adversary); it was polite antagonism of a kind that, at certain moments, managed to breed something peculiarly interesting - moments when, if even for the briefest of times, a compromise had been reached where two or more sets of ideals had met head on and negotiated a way forward that, somehow, managed to preserve the idealism that informed whatever ideologies provided the points of departure. This was an interesting micro-political response, I thought, to the impossible conundrum of democracy - a response that soon fell back into the hubbub of play.

In preparing for this Forum on the Art of Participation, I didn't want to offer solutions to this conundrum - I couldn't claim to have them - but instead wanted to provoke reflection on what the value of compromise might be and mean in the present moment, which is such a charged and unwieldy political moment. (I've since read a brilliant article by Liz Tomlin on Coney's Early Days, and discovered that I'm not alone in wanting to explore some of these ideas). ${ }^{13}$ While I still have faith in the value of dissensus - that frequently elusive, and yet fascinating and powerful gap in the sensible of which Rancière speaks - I wanted to know what others thought about the fetishization of antagonism and opposition in critical theory and its various applications, and who else might be interested in exploring the thorny frustrations and profound difficulties of compromise. 


\title{
An Argument for the Use of Systems Thinking in Participatory Drama Design
}

\author{
Jamie Harper
}

Imagine, for a moment that you're a three-year-old child playing with your toys. You lift the square block and try to put it into the circular hole, but it does not fit. Next, you lift the triangular shape and try again, but still no luck. Finally, you lift the circular object and, hey presto, it drops through the circular hole. Success! The tangible pleasure in this simple play activity comes from the fact that the set of toys is designed to give a clear response to your actions. You try the wrong shape and get clear feedback that it won't fit. You try the right shape and the disappearance of the object tells you that you've succeeded. In fact, the whole world is like this. We take actions and the world gives us feedback on these actions, enabling us to learn and adjust what we do next. Think of Frankenstein's monster, for example. He sees a bright, glowing thing and sticks his hand into it. Immediately, he feels unbearable pain and withdraws his hand. He's been burned and, having experienced this scorching, he won't make the same mistake again.

Arguably, the meaningfulness of our actions in the world comes from the fact that the world responds to these actions. If we did something in the knowledge that the fabric of the universe would not be affected in any way, our action would be meaningless, but we light a fire or press the circular object towards the hole in the hope and expectation that the world will respond to our actions with the outcomes we desire. In this article, I will argue that the meaningfulness of action in works of participatory drama largely depends on the extent to which the fictional world of the drama responds to what participants do, in the same way that the real world responds. I will also make the case that an understanding (and application) of systems thinking, as applied in the field of game design, can be a useful tool for designers of participatory drama, enabling them to construct their fictional worlds as systems that receive, and respond to, the actions of participants, ensuring that these actions have a meaningful impact on the fictional world in question.

To begin with, let me address the question of what "system" means in this context. In Rules of Play: Game Design Fundamentals, Katie Salen and Eric Zimmerman reference social scientist Stephen Littlejohn, who defines a system as a set of interrelated parts that combine to form a complex whole. He identifies four core aspects of a system: the component entities, the attributes of these component entities, the relationships between them and the environment in which they are located. ${ }^{14}$ Using this model, it is possible to analyze practically anything as a system. Take a garden in an allotment, for example. Within 
this system, there are entities like soil, plants or the sun. These entities have various attributes such as the ability of plants to cope with hot/cold weather or the acidity level of the soil. The entities have specific internal relationships, such as the reliance of plants on the energy from the sun; while the environment in which the garden exists could be described by the latitude and longitude of the allotment's location, for example.

This brief explanation of how system analysis works also serves as a brief introduction to the process of game design. In Rules of Play, Salen and Zimmerman argue that all games can be described as interactive systems and, in addition to discussing system analysis as a core component of game design processes, they argue that meaningful play in games is dependent on how well a designed system can respond to the actions of players. ${ }^{15}$ For example, if a video game like FarmVille offers the ability to water your crops, the system of the game should be able to respond to your choice to take this action (or not). So, if you water your plants and see a change in their growth or level of health, this is meaningful play, but if you water your plants and it makes no difference whatsoever, this is meaningless play, since the system of the game has not created a new game state in response to your action.

At this point, having discussed the meaningfulness of action in the real world and within the designed scenarios of games, I would like to give some consideration to meaningful action in participatory drama. A drama has many things in common with a game. Both involve players (or characters) in physical or virtual contexts pursuing goals (or other types of objective) and overcoming obstacles to realize their aims. Dramatic scenarios, like games, can also be analyzed as systems. Let's imagine that we want to conduct a system analysis of the estate of Madame Ranyevskaya from The Cherry Orchard, for instance. In the same way that Stanislavskian "given circumstances" analysis enables us to mine the text of the play for contextual details of place, time and character ${ }^{16}$, a system analysis approach, laying out a picture of the environment of the estate, the active entities (the family members, friends, servants, creditors), their internal relations and attributes, would arguably yield strikingly similar results.

If you have read Chekhov's play, you will know exactly what narrative outcomes will occur, so the performance of the play only requires a qualitative consideration of how the action unfolds, but if you were to create a participatory adaptation of The Cherry Orchard (not that you should, necessarily), it would arguably be necessary to construct a designed system that can respond to the actions of players and allow for genuine uncertainty in the outcomes that emerge. For example, if the character, Yermolai Lopakhin, is to argue that his proposal of cutting down the orchard to build summer villas will solve the financial woes of 
the family, you would probably need to design a simulation of a bank that can actually respond (positively or negatively) to the decision making of the landowner, Madame Ranyevskaya, on what to do with her estate. In other words, if she does decide to cut the orchard down to build the villas, there would arguably need to be some representation of banking institution that can finance the project.

There are, of course, types of participatory drama that will not require a complex system design. A personal role-play of a couple talking about their relationship might not need anything other than the immediate human responses of the two players involved, but if participatory drama makers are designing explicitly political work that deals with political transformation as its subject matter, it might well be useful to create a designed system that can respond to the actions of players and offer the potential of genuine systemic change within the fictional world in question.

In considering the current state of participatory drama practice in the UK, it is difficult to find examples of works that employ system design. The last fifteen years has seen the rise of "immersive" theatre, an amorphous catch-all term that seeks to describe forms of work in which an audience are purportedly immersed within a story world. Most notably, perhaps, Punchdrunk's productions such as Masque of the Red Death and The Drowned Man have created elaborate physical worlds that audience members can explore, encountering performers and snippets of narrative as they choose their pathways. Although the participants in works like these have agency in the sense that they can define their own physical journey through space, they are told that they must not speak and are made aware that they should not enter into the action that they encounter. In a 2014 interview with the UK's Guardian newspaper, Felix Barrett, Punchdrunk's Director, commented in relation to The Drowned Man, that "rather than an audience crafting their own narrative, they are peeling back layers of story, almost archeologically" 17 which neatly sums up the extent of participant agency in the work of Punchdrunk. Audiences are free to explore a space and discover pre-prepared narratives that are architecturally embedded in that space, but there is no affordance for them to influence the dramatic action that unfolds. They can reveal stories for themselves, but they cannot make any impact upon these stories.

The work of Blast Theory contrasts with that of Punchdrunk in the sense that it provides more scope for participants to directly engage with a drama, with performers responding to their actions. In the company's recent piece Operation Black Antler, participants play the role of undercover police officers and are tasked with meeting a range of characters in a pub who might, or might not, be involved in the activities of a militant far 
right organization. Although player actions in this event generate immediate responses from characters within the story world, the larger system does not produce variable narrative outcomes. Ultimately, irrespective of what they do, participants will be told by text message that their mission has been compromised and they will be instructed to leave the pub by their police handlers. So, despite the fact that this piece seems to be strongly interactive, in fact, it is remarkably similar to the structure of the previously cited Punchdrunk works. Participants can excavate details of a pre-prepared narrative by talking to characters within the story world, but their only affordance in shaping an emergent narrative is to vote, during an epilogue-like debrief with the police handler, on whether to place certain individuals under permanent surveillance.

In analyzing these participatory drama works through the lens of game studies, the distinction between a puzzle and a game is instructive. In his book, Uncertainty in Games, theorist and designer Greg Costikyan describes games as state machines, in which the system of interrelated parts that make up the game can respond to player action to generate new game states. For example, in Chess each new move that a player makes produces a new game state, and a series of new game states creates an emergent narrative of how the game unfolds ${ }^{18}$. By contrast, a puzzle, like a crossword, presents a series of problems to be solved, and although the play experience of tackling the puzzle alters as new clues are unlocked, the fundamental structure of the crossword does not change; the solution to a logic puzzle is contingent on the clues provided. The only uncertainty involved is in the solver's ability to sort through the contingencies; or to put it another way, a puzzle is static. It is not a state machine. It does not respond to input. It is not uncertain, and it is not interactive. ${ }^{19}$

This robust assessment of the limitations of puzzles could usefully be applied to many participatory drama works that claim to be interactive. Arguably, in Operation Black Antler, the only uncertainty is in the participant's ability to follow the trail of clues that the actors provide, uncovering the latent story in the same way that the concealed words of a crossword are uncovered. Viewed in these terms, therefore, to paraphrase Costikyan, this work is not a state machine. It does not respond to input. It is not uncertain and it is not interactive.

In considering interactivity and responsive systems in relation to participatory drama, there is much that can be learned from video games, but it would be wrong to assume that the system designs of digital games are always geared towards the facilitation of uncertain emergent narratives. In Half Real: Video Games Between Real Rules and Fictional Worlds, game studies theorist Jesper Juul draws a useful distinction between games of progression, in which players complete a series of tasks to unlock new levels of play that lead in a linear 
process towards the completion of the game, and games of emergence, like Chess, in which the combination of simple rules leads to a vast plurality of potential outcomes. ${ }^{20}$ For example, a game like Super Mario Bros. is a classic game of progression, with the player navigating their avatar in a linear fashion from left to right across the screen, overcoming obstacles and scoring points along the way, prior to a series of battles with "BOSS" figures that lead to new game levels, if the player is successful. In the same way that Costikyan critiques puzzles as fixed systems that do not change, a game like Super Mario Bros. is also relatively fixed in the sense that although the system of the game is constantly responding to the actions of players, the narrative outcome of freeing Princess Toadstool will never change, so the only variability of the game is the extent to which the player is successful in overcoming the obstacles in her path.

More recent developments in video games, including the evolution of Massively Multiplayer Online Role-Playing Games (MMORPGs) or Massively Multiplayer Online Worlds (MMOWs) have suggested new possibilities for the design of complex systems that enable emergent narratives to develop. Play anthropologist Celia Pearce, in her book Communities of Play: Emergent Cultures in Multiplayer Games and Virtual Worlds, gives a fascinating account of the migration of the Uru diaspora from their original game Uru: Ages Beyond Myst into several alternative online worlds including There.com and Second Life. Arguably, the most intriguing aspect of this community migration was that although the players were originally attracted to the immersive experience of occupying the rich visual environment provided by the graphics of Uru: Ages Beyond Myst, in their new virtual homes they came to place greater value on the flexible world building affordances offered by the system designs of There.com and Second Life. ${ }^{21}$ Essentially, whereas the original game presented them with a fixed synthetic world that could not be altered, the new worlds that they moved into provided greater opportunities to build alternative architectural structures and create more complex avatars to represent their individuality and community cultures. In other words, although the initial home of the Uru community was visually beautiful, it was-much like a Punchdrunk space--an unresponsive environment. By contrast, the new worlds that the community entered, though perhaps less visually gratifying, were more systemically responsive; this allowed the fabric of the world to change and players to engage in more elaborate, emergent iterations of their community cultures.

Clearly, designers of computer games and virtual worlds have the opportunity to build highly complex systems using digital code. The level of intricacy that digital design can accommodate, however, is arguably out of reach for non-digital designers, which raises the 
question of how theatre makers can design for emergent complexity. In my work as a designer of participatory drama, I have sought to address the issue of participant agency by learning about game design in its analogue incarnations and applying systems thinking in the development of my projects. Following two research residencies at the University of Miami in 2013 and 2014 (both of which were focused on the merger of games and drama), I made two explicitly political games: Archipelago, about a group of islands and their inhabitants trying to recover from a drought; and People Vs Democracy, about the citizens of a miniature country seeking power through economic strength. Both of these games were designed as systems with complex game mechanics (the levers of power with which players can exert influence on the system) and detailed sets of rules as constraints to player action. From my perspective, the good thing about these games was that they were entirely free from any fixed narrative. Instead, the game systems responded to the actions of participants to create emergent player driven narratives that transformed the islands in Archipelago, or the miniature country of People Vs Democracy, in highly unpredictable ways.

Subsequently, my interest has moved towards Nordic Larp (live action role-play), a form of participatory drama that has emerged in the Nordic countries over the past two decades. In contrast to conventional game design, larp tends to have a very light emphasis on system design with very few rules, and a greater focus on creating a dramatic framework in which participants can create emergent character-driven narratives through co-operative play. My exposure to larp prompted the design of The Lowland Clearances, a piece about the displacement of people in $19^{\text {th }}$ century London to make way for various forms of industrial development. This piece focused more strongly on facilitating inter-personal drama than my previous game projects, but it retained a systemic frame in the form of six pre-authored narrative events which could be triggered in response to variations of the game state. For example, if players prioritized economic development, a railway would be built, but if they were concerned with public health, a sewerage system would be introduced. These changes would subsequently alter the contextual circumstances of play, creating new game states in the lives of each individual character. Essentially, this design enabled the combination of emergent character-driven micro-narratives, alongside the development of a systemic macronarrative of urban transformation.

Another good example of a larp that combines emergent player-led narratives with a larger system based narrative is Just a Little Lovin', a hugely influential project about the AIDS epidemic in 1980's New York. This larp employs a simple three act structure, charting the life of New York's gay community over three years. In the first act, the theme is hedonism 
and players have the opportunity to find love and have sex with as many people as they want. This player action (of having sex or abstaining) has the systemic impact of increasing or lessening their relative risk level of contracting HIV and although this larp is about a lot more than the basic question of who lives and who dies, it serves as a good example of a simple system design that ensures that player actions have an integrated impact on the overall story world, directly influencing the core narrative outcomes of death or survival. There are many other larps that successfully combine system design with intimate human drama and the limited scope of this piece can only scratch the surface of what has been achieved by larp designers, but I hope that these references serve as a stimulus for curious readers to discover more about the rich design histories of live action role-play in the Nordic tradition.

For artists from a theatre background, the idea that they might usefully apply system analysis and system design in their work might seem an unusual suggestion, but if the meaningfulness of action rests upon the responsiveness of the world around us, and if drama seeks to represent the world, I think that participatory dramas need to be just as responsive to player action. System design is at the heart of game design and game designers are experts in creating interactive play, so if participatory artists really want to facilitate the agency of participants, they could do worse than learning how to apply system design.

So, let me conclude with a challenge to the reader: pick any real world system (a school, a business, a church) and do a system analysis of it, identifying the active entities of which it is composed, the attributes of those entities, their internal relationships and the environment that they inhabit. Then, take a deck of cards and design a game based on this system analysis. This game might be good, bad or indifferent, and it might be a long way from a participatory drama, but as long as it is designed in such a way that players can take actions that are meaningful, with a discernible and integrated impact on the system of the game, it's a good start.

\title{
SECTION 4: INSTRUCTIONS
}

\section{Walkshop and Soundshot - A Dérive and Participatory Performance}

\author{
Sonia Overall
}

\section{The Walkshop}

My current practice-based research draws upon the relationship between psychogeographical theory and creative writing methods. I am interested in the relationship 
between walking and ideation, and how embodied experience of place informs creative work: the formal possibilities that walking and psychogeography offer contemporary writing, and ways in which narrative form can be used to represent or respond to place.

\title{
Walkshop: individual dérive and information capture \\ Participants meet centrally and are given a set amount of time to walk individually around campus (5-10 minutes, depending on schedule). \\ Participants dérive or drift, driven by their own individual curiosity and interpretation. Prompt cards with randomly-generated directions help lead the participants away from established or habitual routes.
}

Psychogeography offers ways of re-examining place and our relationship with it. Psychogeographical exercises encourage the walker to question what they see and the paths they usually take: to reject routes, disobey signage, and follow their curiosity. Through attentiveness, the dérive or $\mathrm{drift}^{1}$ establishes itself as other than a casual stroll or a means of travelling from one point to another.

\author{
Turn to your left. Walk straight on. \\ $\rightarrow$ First left \\ $\rightarrow$ Second right
}

Keep going straight as far as you can.

Since its earliest Lettrist and Situationist forms, ${ }^{2}$ psychogeography has employed devices and "catapults" to break habitual patterns of walking and, by extension, being. In "Formulary for a New Urbanism", Chtcheglov rails against the "mental disease" of "banalization," of a society "hypnotized by production and conveniences... Presented with the alternative of love or a garbage disposal unit, young people of all countries have chosen a garbage disposal unit."4 Chtcheglov's answer is to radically reconstruct society from the ground up, challenging the urban environment through transformable, shape-shifting architecture and the development of districts designed to correspond to "the whole spectrum of diverse feelings," 5 from the Bizarre to the Sinister. In this new society, "[t]he main activity 
of the inhabitants will be CONTINUOUS DRIFTING' with the aim of shifting individuals from their apathy through "total disorientation." ",

\author{
Walk in the direction you are facing. \\ $\rightarrow$ At the end of this street, flip a coin: \\ if heads, walk on; if tails, walk back to the previous junction. \\ $\rightarrow$ First left \\ Repeat directions.
}

Total disorientation may not be possible in the space of a two-hour seminar, but by integrating dérives into creative practice, one can defamiliarize place and find new ways of experiencing, and thus seeing, the everyday. This is the thinking behind my incorporation of psychogeographical exercises into my own writing and my creative writing teaching. Disrupted walking methods and dérive-based exercises present possibilities to all creative and site-specific practices: for recent examples, see Wrights \& Sites’ A Mis-Guide to Anywhere ${ }^{7}$ and Clare Qualmann and Claire Hind's Ways to Wander. ${ }^{8}$

\title{
The Soundshot
}

As a writer and tutor of creative writing, I am often presented with the expectation that writing is a solitary, internal process. Author readings focus on the delivery of finished work to an audience: the creative workshop, while a communal, participatory experience, can be an ordeal for the self-conscious student. As a tutor, I strive to find ways of making the act of creating and sharing text as painless as possible, and often use performance-based approaches to help deliver this. I am particularly interested in how the act of participation can be shaped to assist students, and other nervous writers, to gain confidence with sharing their work, using their voice and ultimately, performing to an audience.

Building upon some of my existing ice-breaker exercises, I devised the 'soundshot' element of this workshop when working on a single day in 2015 with an interdisciplinary group of postgraduate students. The day consisted of a series of dérive-based exercises in Canterbury, designed to encourage sensory exploration, observation and interpretation of place. The soundshot replaced the usual plenary discussion at the end of the day: rather than asking the students to speak individually about the experience or share any draft creative work, I asked them to offer their observations all at once. The students had worked in small 
groups and as individuals. For the last exercise, each participant noted down found sounds within an identified location and timeframe.

\section{Soundshot: collage of interpreted sound, performed by the participants}

At an agreed time, all participants stop walking and mark their location on a map of the campus. They then write down every sound they hear in the following 60 seconds.

Participants reconvene at an agreed location. They perform a soundshot of the campus by reading simultaneously from their recorded notes, creating an ephemeral, sitespecific collage of interpreted sound.

Gathering together back on campus, participants stood at a point in the room which they felt represented their location in the town. All participants read aloud their notes, raising and lowering their voices according to the volume or type of sound transcribed. This shared reading became increasingly performative as individuals embodied sounds, vocalized noises and transposed the soundscape of a busy Saturday city center to an anonymous seminar room. At the end of the soundshot it was clear that the participants were experiencing the adrenaline and buzz of performance, speaking with great animation about their own and each other's delivery as well as the material shared. Moving and speaking together had not only helped with group identity and bonding, the act of participation had become a form of shared aesthetic experience.

For the Art of Participation Forum, I developed the original soundshot into a two-part workshop: a dérive with a sixty second, site-specific sound transcription, followed by a collaborative performance of the soundshot. Participants drifted on the University of Kent campus, following their curiosity or prompted to wander by random direction cards. 
After five minutes of walking, stop. Make a note of your location on the campus map. This is the location of your soundshot.

Spend some time inhabiting this final place. Listen carefully to your surroundings. Close your eyes. Be still. Tune in.

At the agreed time, write down EVERYTHING you can hear, however garbled or fragmentary: snatches of conversation, song lyrics, announcements, footstep sounds, birdsong, machinery noise etc. Record onomatopoeic renderings of sound (e.g. cluk-clukcluk of heels on pavement, the fuuuuuugh of a bus putting on its brakes). Do this for ONE MINUTE.

At the agreed time participants gathered on the outdoor labyrinth to perform the soundshot, the chosen site serving as a stage for the creation of a site-specific sound collage.

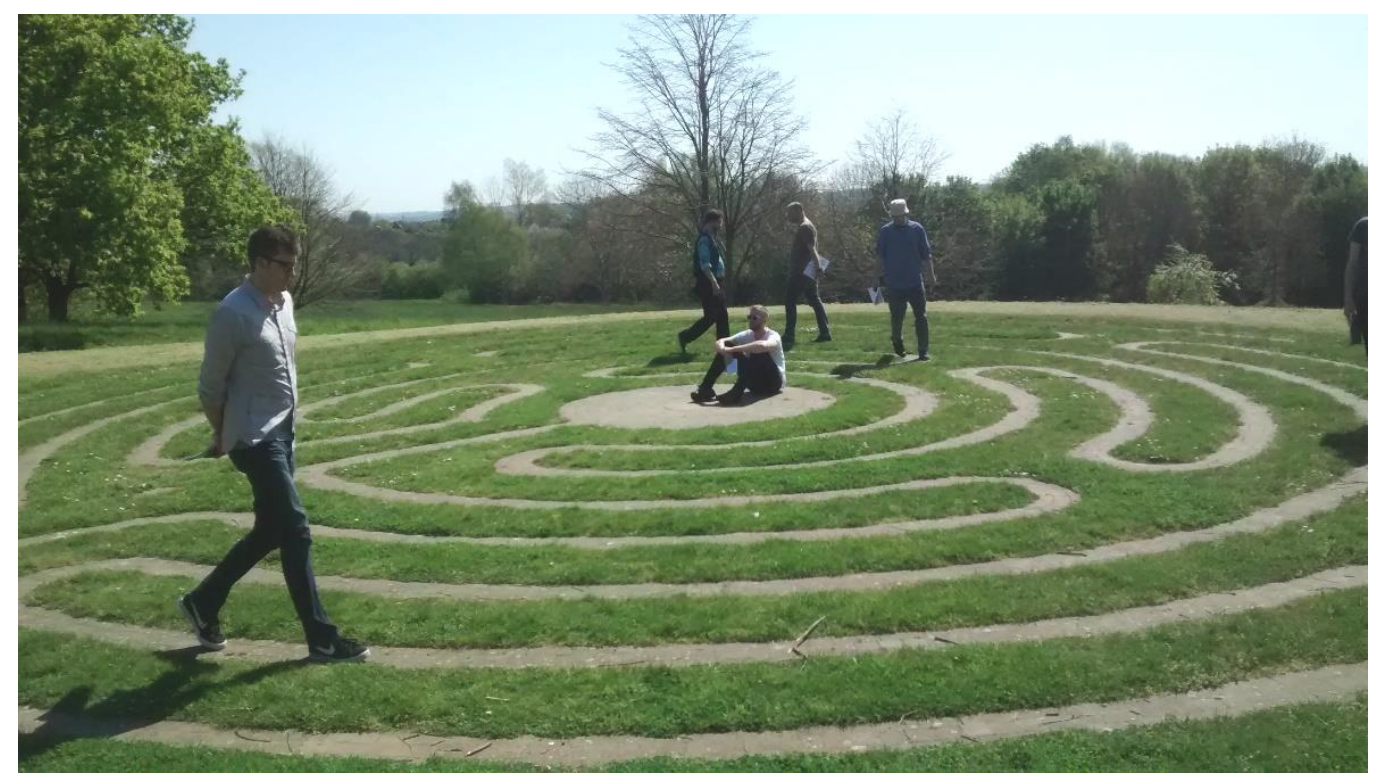

Photo 1: Participants begin gathering at the Kent labyrinth to perform the soundshot 


\section{We Did That: (Not) @Home II}

Emma Gee

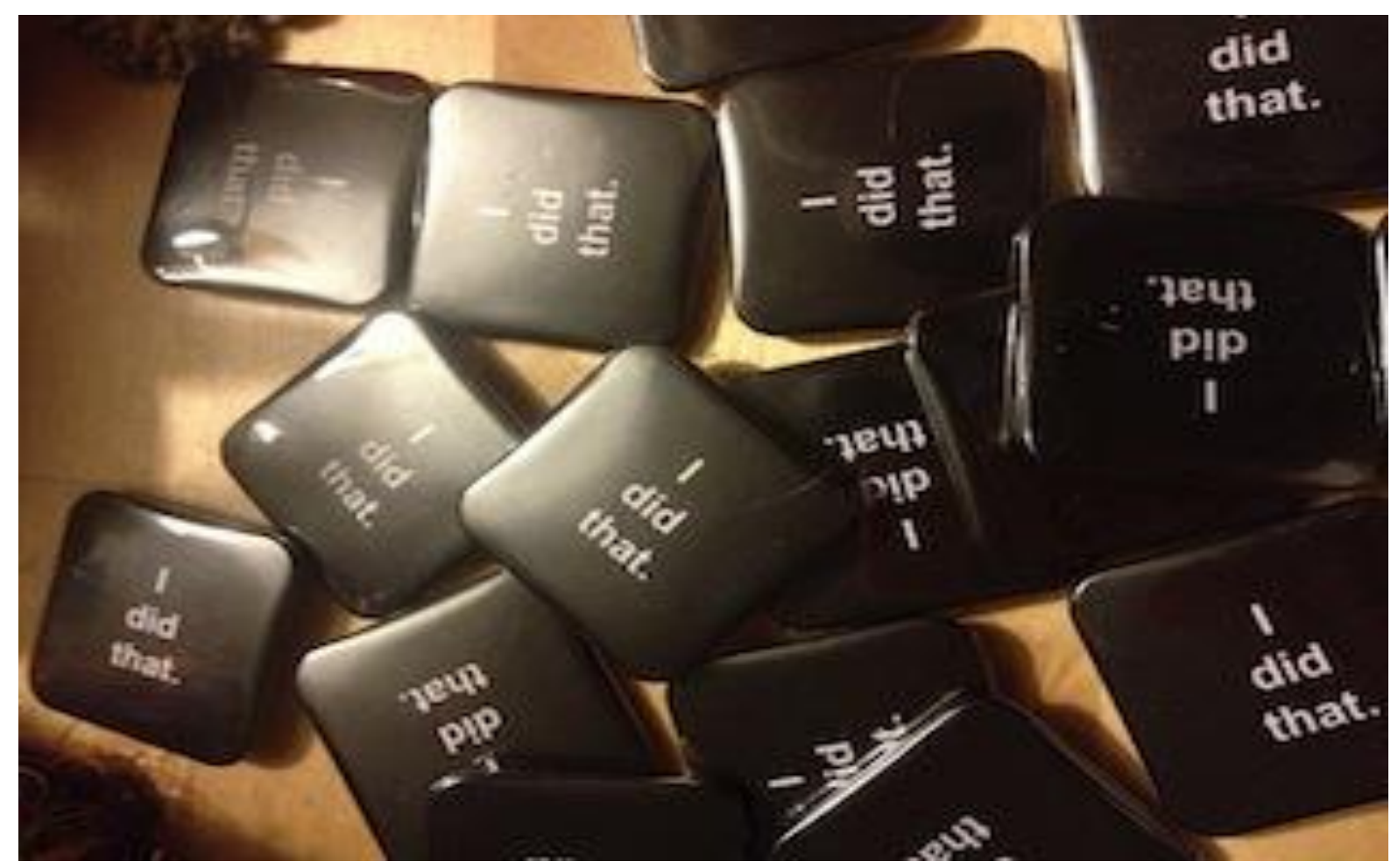

Why do I hate participation and yet foist it on others?

This work aimed at prompting participant risk by operating in the "real'9 and not solely the aesthetic realm.

Is this ethical? Is it ethics in the making?

(Not) @Home II was:

- An invitational participative exercise using:

- A large space to play, with a lot of floor

- A floor you can put masking tape on and not upset anybody

- Lots of masking tape

- Other people's stuff

- In four parts, each with an invitation within an envelope placed in the space by the artist prior to the event (see below)

- Run for an hour, more or less 
(Not) @Home II Instructions:

\section{Envelope A:}

Who would 'find' the envelope, open and read it? Take control? Set things in motion?

(It was Astrid who took the initiative.)

Please Open Now

Would this event 'start?' If it didn't would that be the event? Would it still be the event if we didn't even talk about it? Would this be event aesthetics?

The moments before Astrid opened the first envelope people sat on the chairs at the perimeter of the room, as if in a waiting room, including me. It would have been interesting to see how long everyone was prepared to 'wait'.

\section{Welcome to@Home 1}

Why the 'Participative Turn' instigated by avant-garde artists in the 60s? What is it we want from our 'audiences'?

- Please take a roll of masking tape.

\section{I don't want audiences.}

- Use the masking tape to tape on the floor a 'home'. This could be a plan of your actual home or a fantasy home, room, territory or space

\section{I want (co)authors/directors/artists.}

- Please use the pens provided to write on your tape with information, explanation, instruction and invitation for your home

\section{I want 'pro-active' engagement.}

- You may find making your home requires the negotiation of boundaries or space sharing I want dialogue. (I note the irony.)

- You have 25 minutes to complete this task. Can someone in the group set a watch or phone as timer for this?

The 'Butlers' undertook timings (with gold fob watches) thereby providing the event with a complementary 'service' without knowing the source of the request--thus one piece of participation bled seamlessly into another, enabling its facilitation. Elsewhere 1:1 
engagement took place concurrently and people came and went from the room throughout resulting in more facilitation and interweaving.

- Have fun home-making.

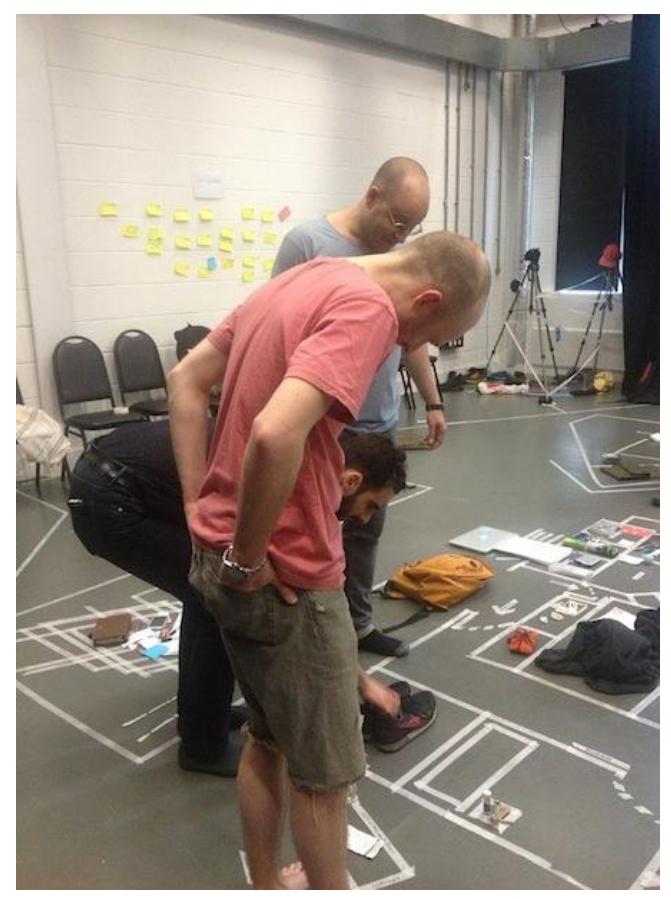

A neighbor: "We haven't talked about our boundary line."

Answer:

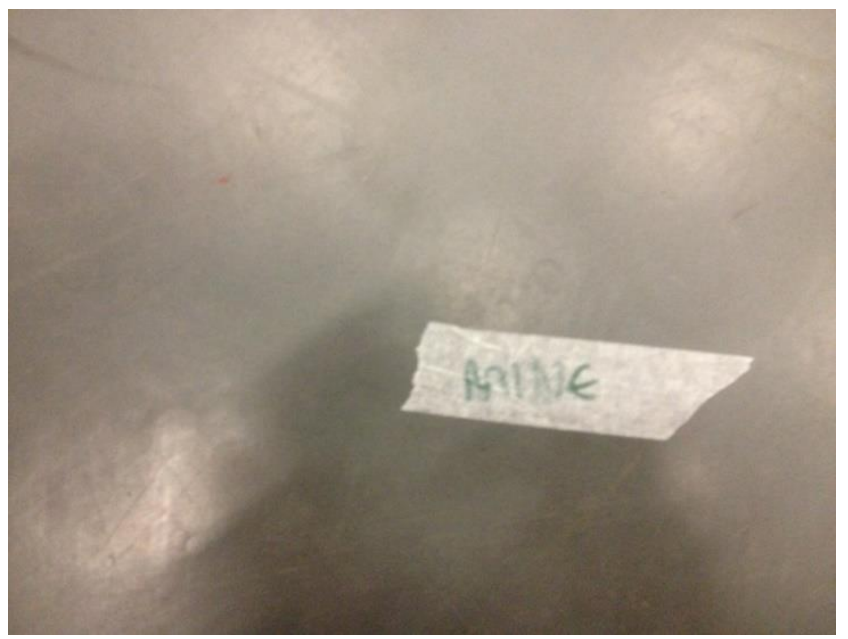

One 'home' escapes boundaries altogether: out of the studio, up the corridor, into the lift, up two floors and out into another corridor and 'through' a window...

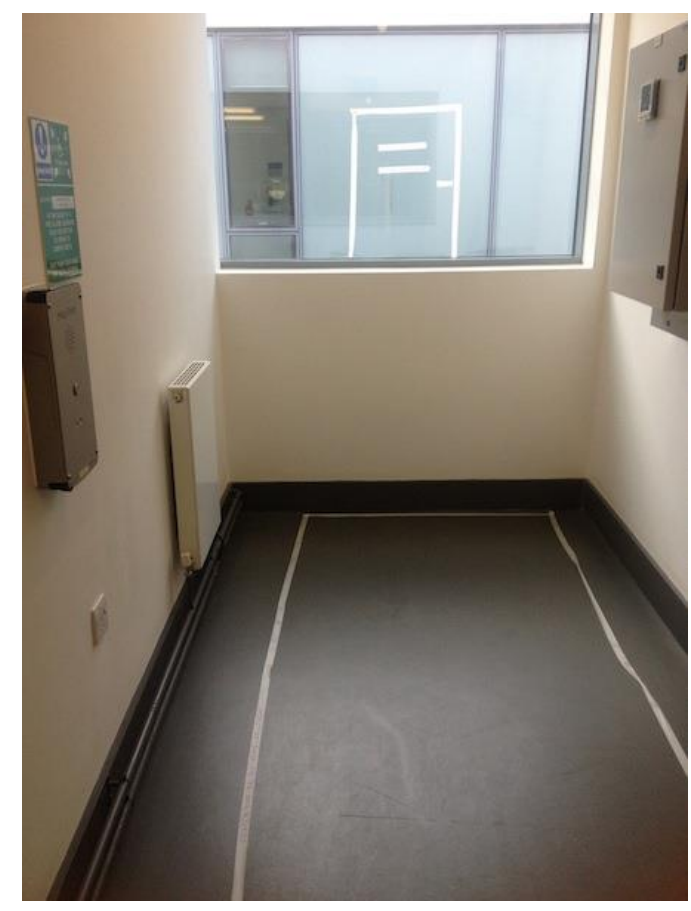

"There's more tape if you need it"

\section{Do I hate participation?}

I find it intensely difficult.

\section{Why am I still doing it?}

I sought anonymity within this work in order to participate alongside everyone else on (relatively) equal terms - certainly NOT as an agent provocateur, more agent timid. I remained anonymous throughout the event. There was no grand reveal, some people found out afterwards. Possibly some people still do not know.

\section{Is this ethical? Is it ethics in the} making? 
I enjoyed participating in this. I had my head down for less than a minute taping a rectangle, looked up and a metropolis had emerged! The space had erupted into activity. Conversations had started. I listened (and joined in).

\section{Is this ethical?}

It was out of my hands. I will never know it all, or even the half of it.

Is this ethics in the making?

\section{Envelope B:}

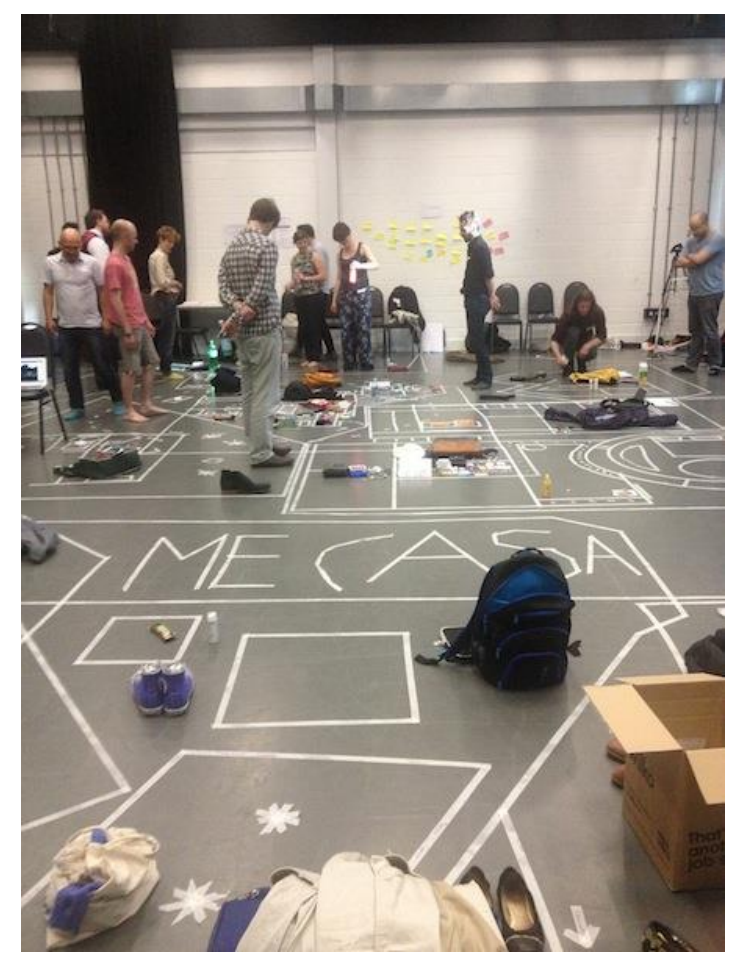

Please open when the first timer goes in 25 minutes

Are participative practitioners running to keep up with participants? Are we operating a rear-guard and adopting/adapting from the mainstream to keep up with participant demand? Is this a new avant-gardism? Is it a hybrid? Does it matter?

\section{Welcome to@Home 2}

- Please spend the next 5 minutes populating your 'home' with all the belongings you have with you today

- Please empty out bags, pockets, open up lap-tops and phones and generally expose your stuff within your 'home,' as if you were at home

- You have 5 minutes to complete this task. Can someone in the group set a watch or phone as timer for this?

- Have fun 'nesting'

My immediate neighbor tears his tape up off the floor--he has rethought his roof design. The new version opens to the elements.

Is there agency here? If so, how did it establish and manifest itself? 
In the far corner someone builds a "flat" the size he thinks he could afford in London--his toilet is actual size and his feet have to sit in the cooker when he lies down.

If there is no agency, why not?

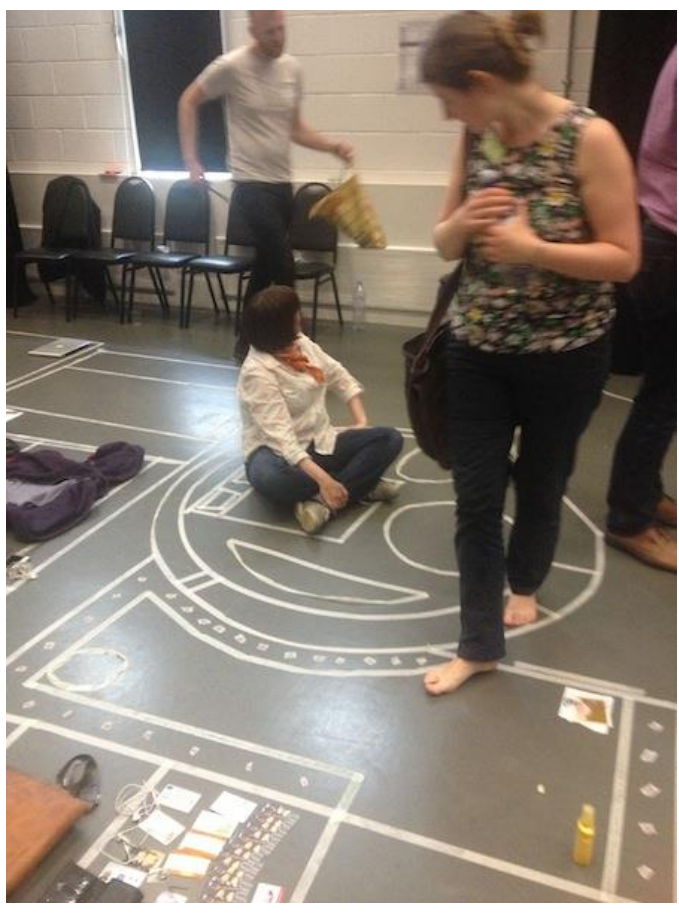

The minimalist Tree House wasn't intended to be minimalist - its creator had popped out to do the $1: 1$ project briefly and missed the instructions. He expressed regret.

I said: "What's stopping you now?

He said: "Oh nothing. (Smiles). I'll get my bag."

(I'm being provocative).

Is this ethical? Is it ethics in the making?

\section{Is my provocation coming from my original authorship or from my participation?}

The agency paradox: agency cannot be afforded, gifted, given or directed. Astrid offers "conducted" as in electricity, not like an orchestra. Presumably I can restrict, remove, thwart, block and refuse agency as the originating author/director/artist and as participant (is that my agency?).

\section{Is this ethical? Is it ethics in the making?}

I ponder my role.

\section{How do I provoke 'pro-activity' in this and other work and resist authorship?}

I'm in a bind. Excellent!

Victor takes me on a guided tour - such pride. (We both have pools).

\section{Envelope C:}

Please open when the second timer goes in a further 5 minutes

Welcome to (Not) @ Home 
- Please leave home.

- Go visiting your neighbors (whilst they are away)

- You have 25 minutes to complete this task. Can someone in the group set a watch or phone as timer for this?

- Have fun visiting

Participant 1: "We can't go into other people's houses, that's breaking and entering."

Participant 2: "It's in the instructions: visit whilst they are away."

Participant 1: "Oh that's okay then."

Is it though? Is it ethical? Is it ethics in the making?

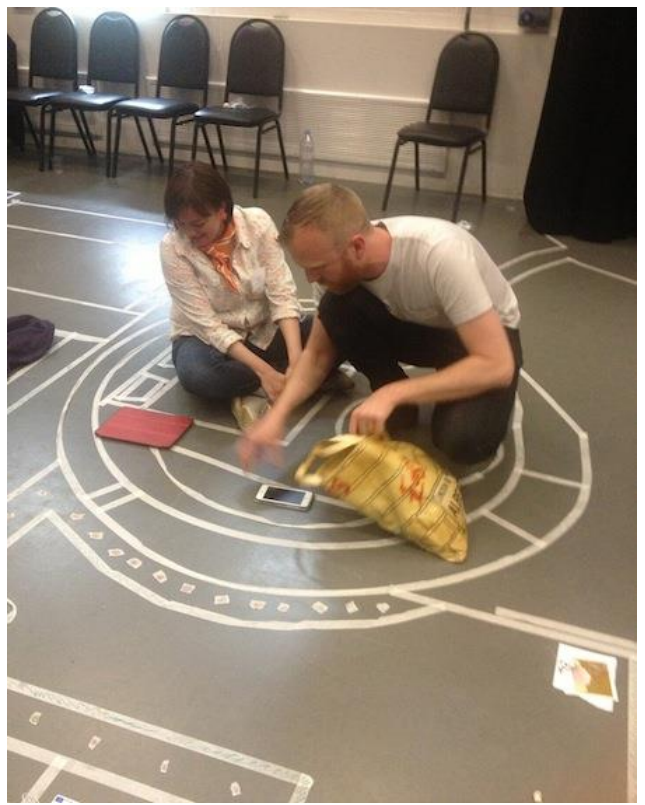

At the Tree House a "squatter" resists the creator's attempts to populate the space with his effects:

Squatter: "It looks better empty."

Creator: "But I want to put my stuff in here."

Who governs meaning making now? Who did before?

In another 'home' I am opening someone's wallet and laying out all his bank and business cards on the floor (I also find his lost headphones in his bag). He is watching me from across the room and calls out:

Home owner: "What are you up to?"

I: "You are not in, you can't see me!"

I'm being provocative (again).

What is happening to authorship and dialogue here?

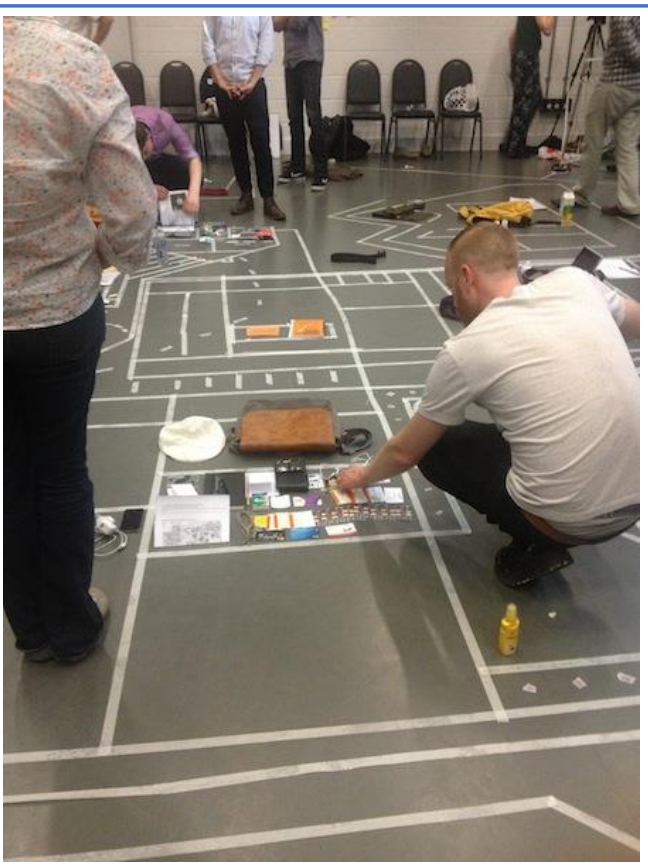

Are we regretting participation now? 
In the home with the visitor's book and complimentary mints, there is not enough participation for the host - he wants more. He has "borrowed" an artefact from another house to "venerate."

\section{Is he being provocative? Is this ethical? Is it ethics in the making?}

The following day his own provocation delivery is sited on the "ghost" of his plot. He invites us to come and sit in his 'home'.

\section{Envelope D:}

Please open when the third timer goes in another 25 minutes

\section{Welcome Back Home}

- Go back home

- You have 5 minutes to complete this task. Can someone in the group set a watch or phone as timer for this?

- When the timer goes the event is completed

- Many thanks.

Where does this keenness to actively 'do' spring from? Do we want to watch anymore?

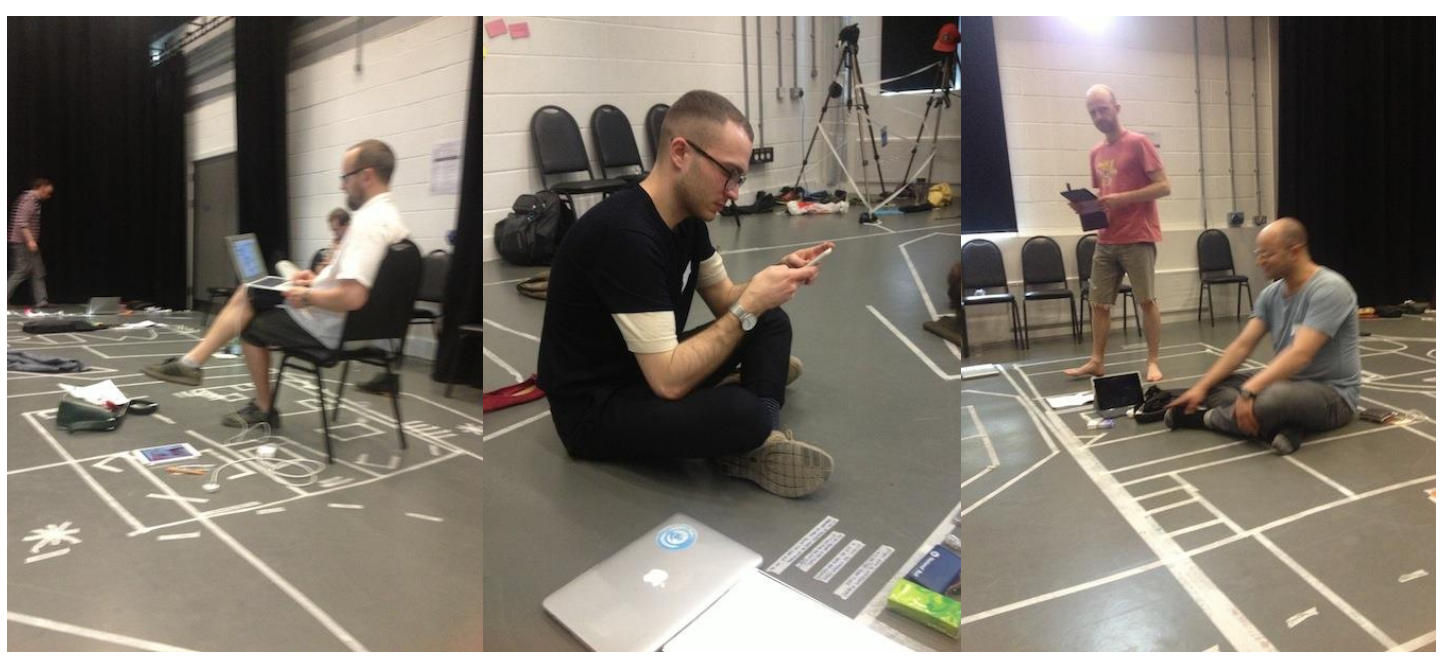


The 'return' seems very calm: neighborly chatting, noticing 'disturbances,' tidying up, and resting - re-connecting.

\section{Are we participant-led now?}

I keep coming back to the notion that participation requires a catalyst.

\section{Is this authorship? Where does that leave the event aesthetics director?}

Robbie would like to borrow my wet-wipes. (I become suddenly aware of how much 'medical' stuff I had in my rucksack that is now out on display). He does (but I don't know what for).

\section{What are the consequences of participation?}

Where will it end? Will it end?

Was this ethical? Was it ethics in the making?

If you want to provide answers, further questions and other provocations in response to this event please contact me on: gee.e@tiscali.co.uk

Go on. Participate.

Copyright for all images: Emma Gee

\section{How to Make a Forum}

\section{Astrid Breel, Hannah Newman and Robbie Wilson}

We believe the Forum format to be readily transferable across the Arts. How to create a participatory forum in 8 easy steps:

Don't spend hours trying to find a singular meaning/definition of the area of the arts that you are interested in. Instead, leave it as an open-ended provocation in your callout to draw in as many different viewpoints as possible.

Spread the call-out far and wide to encourage many different voices to participate.

$>$ Think carefully about getting the balance between academe and practice. We used five minute provocations and thirty-minute workshops, plus spaces for performances. 
$>$ Once you have received all the submissions, group them together thematically. They may complement or contradict each other, but doing this will help you to see who would be most appropriate for your forum.

$>$ Program the event so that each participant contributes something during the event.

$>$ We had a Keynote Doer and Responder (instead of the traditional Keynote Speaker), which framed the event and helped further this notion of participation.

$>$ Allow more space than you think you will need for discussion.

$>$ During the day have a horn to keep people on time (although after an initial demonstration, we only ever had reason to use the horn playfully).

$>$ Make sure there is a wealth of tea, coffee, biscuits and cake.

\section{CONCLUSION}

This journal section, like the Forum itself, has explored practical and theoretical considerations relating to PP, with a particular focus on how they shape and influence the work's aesthetics. Through reflections, explorations, and instructions, we have mapped a multitude of pathways through this distinctly heterogeneous terrain. The final event of the Forum was a practical, plenary-style session in which Gareth White (as Keynote Responder) led us through a series of summative investigations intended to pull together the central threads that had emerged from the weekend's activities.

Gareth identified six such threads, which he perceived as having run throughout the Forum's workshops, performances, and discussions. They were: Time, Story, Intimacy, Publicness, Impact, and (perhaps the most central thread of all) Agency. We suggest that these themes provide valuable avenues along which to focus future research into PP. The way in which the Forum's summative investigations took place foregrounded the dialectic nature of the Forum as a whole; the entire event was structured so that at no point did participants simply talk at one another. The plenary session continued this dialogue in dynamic and practical fashion, as Gareth challenged us to render, spatially and bodily, the Forum's varied and heterogeneous relationship to the above six themes. This was attempted by successively positioning ourselves within the space along vectors which represented questions pertaining to each of the themes. The ensuing arrangements of bodies could then be said to roughly represent the spectrum of relationships that participants of the Forum, and their respective practices, bore to the selected themes. 
For each theme, we were asked to consider a piece of PP in respect of that particular variable. For example, when addressing the Time theme, we arranged ourselves according to the duration of a particular work we had at some point created or experienced. Much existential torment was experienced as participants struggled to decide where to place themselves on each vector, powerfully and affectively foregrounding the immense difficulty of defining, or even clearly mapping, the territory of PP from an aesthetic standpoint. Though there are no clear answers, much was discovered. One of the chief findings from the Forum was, firstly, just how wide and varied the field of PP is and, secondly, the discovery of recurring patterns and similarities of interest across these practices, as well as within those that revealed themselves to be internally heterogeneous. For instance, agency appears to be a common concern across all practices that identify with PP. Finally, the interdisciplinary discussions and practical engagements yielded realizations which resulted in the first steps towards meaningful, practical cross-pollination within and between forms of PP. We hope that this process may continue and that our Forum will not be the last.

\section{Notes to Section 1: Introductory Material by Breel, Newman, and Wilson}

${ }^{1}$ You can see and download the CFP here: https://forumonparticipation.files.wordpress.com/2016/02/cfp_screen1.pdf

${ }^{2}$ The impact agenda in the UK pertains to both academia and the arts. It constitutes the latest development in a drive by government for universities and artists to be everincreasingly accountable for their public funds. In Higher Education, this drive has been ongoing since the 1980s and is becoming increasingly complex, onerous, and problematic (Martin, Ben R., The research excellence framework and the 'impact agenda': Are we creating a frankenstein monster? Research Evaluation 20 (3), 2011). The Research Excellence Framework, or REF, in 2014 was the first UK research audit to explicitly assess extra-academic impact, defined as "an effect on, change or benefit to the economy, society, culture, public policy or services, health, the environment or quality of life, beyond academia" (HEFCE. REF impact - higher education funding council for England, (2016). Available from http://www.hefce.ac.uk/rsrch/REFimpact/ (accessed 5/31/2017)). The case is similar in the arts, with the funding body, Arts Council England, focusing its investment "where it can achieve the greatest impact" (ACE. Great art and culture for everyone.pdf in Arts Council England [database online], (2013) Available from http://www.artscouncil.org.uk/sites/default/files/download-

file/Great_art_and_culture_for_everyone.pdf (accessed 5/31/2017).). Whilst the impact agenda arguably marginalizes aesthetic considerations across the board, in participatory arts, where material production tends to be less important than interaction and experience, we argue that the impact agenda has led aesthetics to become especially neglected. This is all the more unfortunate considering that the impact agenda implicitly valorizes participatory arts, rendering consideration of their aesthetics a pressing concern. 
${ }^{3}$ Simon Shepherd and Mick Wallis, Drama/Theatre/Performance (London: Routledge, 2004), 220-4.

${ }^{4}$ Gareth White, Audience Participation in Theatre: Aesthetics of the Invitation (Basingstoke: Palgrave Macmillan, 2013), 5.

${ }^{5}$ Richard Sallis, "Ethnographic Performance: A Change Agent for Drama Teaching and Learning," RiDE: The Journal of Applied Theatre and Performance 19, no. 3 (2014): $317-8$.

${ }^{6}$ Rosemary Klich, and Edward Scheer, Multimedia Performance (Basingstoke: Palgrave Macmillan, 2012), 176.

${ }^{7}$ Claire Bishop, Artificial Hells: Participatory Art and the Politics of Spectatorship (London: Verso, 2012), 1.

${ }^{8}$ Jen Harvie, Fair Play: Art, Performance and Neoliberalism (Basingstoke: Palgrave Macmillan, 2013), 28.

${ }^{9}$ Josephine Machon, Immersive Theatres: Intimacy and Immediacy in Contemporary Performance (Basingstoke: Palgrave Macmillan, 2013), 99.

${ }^{10}$ Adam Alston, Beyond Immersive Theatre: Aesthetics, Politics and Productive Participation (Basingstoke: Palgrave Macmillan (2016), 46.

${ }^{11} \mathrm{PaR}$ refers to research whereby (predominantly artistic) practice is the chief methodology and is thus productive of knowledge. See Nelson (2013) Practice as Research in the Arts for a key reference text and Riley \& Hunter (2009: xv-xix) Mapping Landscapes for Performance as Research for comparison and contrast between PaR and performance-as-research (PAR), as well as other formulations.

${ }^{12}$ Coney: REMOTE

\section{Notes to Section 2: Reflections by Condit, Fletcher, and Titley}

${ }^{1}$ Claire Bishop, “Antagonism and Relational Aesthetics,” October 110 (2004): 51-79.

${ }^{2}$ Adam Alston, Beyond Immersive Theatre (London: Palgrave Macmillan, 2016).

${ }^{3}$ Jen Harvie, Fair Play - Art, Performance, and Neoliberalism (London: Palgrave Macmillan, 2013).

${ }^{4}$ Marina Abramovic, Rhythm 0. Originally performed in 1974, Studio Morra, Naples. Websource Marina Abramovic Institute, https://vimeo.com/71952791, accessed 30th March 2017.

${ }^{5}$ Robin Bauer, Queer BDSM Intimacies: Critical Consent and Pushing Boundaries (London: Palgrave Macmillan, 2014), 182.

${ }^{6}$ Julius Elo and Tuomas Laitinen, Circle. Working group: Outi Condit, Julius Elo, Annamaria Häkkinen, Tuomas Laitinen and Jarkko Partanen. (Reality Research Centre, Helsinki, 2013).

${ }^{7}$ Henri Lefebvre, Critique Of Everyday Life Vol 1. (Paris: Verso, 2014), 638.

${ }^{8}$ Michael Polanyi, The Tacit Dimension (Chicago: The University of Chicago Press, 2009), 68. 
${ }^{9}$ Grant H Kester, Conversation Pieces : Community and Communication in Modern Art (Berkeley and Los Angeles London: University of California Press, 2004), 113.

${ }^{10}$ Lefebvre, 630.

${ }^{11}$ Tim Ingold, Making: Anthropology, Archeology, Art and Architecture (London: Routledge, 2013), 31 .

${ }^{12}$ Ibid., 25.

\section{Notes to Section 3: Explorations by Anderson, Alston, and Harper}

${ }^{1}$ Astrid Breel, "Aesthestic Relationships and Ethics in The Oh Fuck Moment," RiDE: The Journal of Applied Theatre and Performance 20 no.1 (2015): 46.

${ }^{2}$ Ibid., 40.

${ }^{3}$ Gareth White, Audience Participation in the Theatre: Aesthetics of the Invitation (Basingstoke: Palgrave Macmillan, 2013), 82-83.

${ }^{4}$ Ibid., 1.

${ }^{5}$ Richard Schechner, Performance Theory (London; New York: Routledge, 1988), 220.

${ }^{6}$ Joesphine Machon, Immersive Theatres: Intimacy and Immediacy in Contemporary Performance (New York; London: Palgrave Macmillan, 2013), 43.

${ }^{7}$ Tassos Stevens, quoted in Machon, 199.

${ }^{8}$ White 90.

${ }^{9}$ Ibid., 73.

${ }^{10}$ Ernesto Laclau and Chantal Mouffe, Hegemony and Socialist Strategy: Toward a Radical Democratic Politics (London: Verso, 1985).

${ }^{11}$ Jacques Rancière, Dissensus: On Politics and Aesthetics, ed. and trans. Steven Corcoran (London: Continuum, 2010).

${ }^{12}$ Adam Alston, Beyond Immersive Theatre: Aesthetics, Politics and Productive Participation (London: Palgrave Macmillan, 2016).

${ }^{13}$ Liz Tomlin, "'Constellations of Singularities': The Rejection of Representative Democracy in Coney's Early Days (of a better nation)," Studies in Theatre and Performance 36, no. 1 (2016): 27-34.

${ }^{14}$ Katie Salen and Eric Zimmerman, Rules of Play: Game Design Fundamentals (Cambridge MA: MIT Press, 2004), 214-215.

${ }^{15}$ Ibid., 32-35.

${ }^{16}$ Konstantin Stanislavsky, An Actor Prepares (New York: Theatre Art Books, 1936), 70.

${ }^{17}$ Thomas McMullan, "The Immersed Audience: How Theatre is Taking its Cue from Video Games" The Guardian, May 20, 2014. Accessed March, 22, 2017, https://www.theguardian.com/technology/2014/may/20/how-theatre-is-taking-its-cuefrom-video-games.

${ }^{18}$ Greg Costikyan, Uncertainty in Games (Cambridge, MA: MIT Press, 2014), 39.

${ }^{19}$ Ibid., 14. 
${ }^{20}$ Jesper Juul, Half-Real: Video Games Between Real Rules and Fictional Worlds (Cambridge MA: MIT Press, 2005) 78.

${ }^{21}$ Celia Pearce, Communities of Play: Emergent Cultures in Multiplayer Games and Virtual Worlds (Cambridge, MA: MIT Press, 2009) 125-137.

\section{Notes to Section 4: Instructions by Overall, Gee, Breel, Newman, and Wilson}

${ }^{1}$ Guy Debord, "Theory of the Dérive," in Situationist International Anthology, ed. and trans. Ken Knabb (Berkeley: Bureau of Public Secrets, 2006), 62-66.

${ }^{2}$ See Ken Knabb, ed. and trans., Situationist International Anthology (Berkeley: Bureau of Public Secrets, 2006).

${ }^{3}$ Ivan Chtcheglov, "Formulary for a New Urbanism," in Situationist International Anthology, ed. and trans. Ken Knabb (Berkeley: Bureau of Public Secrets, 2006), 1-8.

${ }^{4}$ Ibid., 4.

${ }^{5}$ Ibid., 6.

${ }^{6}$ Ibid., 7.

7 Stephen Hodge et al., A Mis-Guide to Anywhere (Exeter: Wrights \& Sites, 2006).

${ }^{8}$ Clare Qualmann and Claire Hind, eds., Ways to Wander (Axeminster: Triarchy, 2015).

${ }^{9}$ In this contribution, inverted commas are used to draw attention to multiple readings of a word or phrase, in contrast to quotes or direct speech, which are indicated by double quotation marks. 